\title{
Renting versus Owning and the Role of Human Capital: Evidence from Germany
}

\author{
Rainer Schulz, Martin Wersing, and Axel Werwatz*
}

21 February 2013

\footnotetext{
* Schulz and Wersing: University of Aberdeen Business School, Edward Wright Building, Dunbar Street, Aberdeen AB24 3QY, United Kingdom. Emails: r.schulz@abdn.ac.uk and martin.wersing@abdn.ac.uk. Werwatz: Technische Universität Berlin, Institut für Volkswirtschaftslehre und Wirtschaftsrecht, Straße des 17. Juni 135, 10623 Berlin, Germany, and Collaborative Research Center 649 Economic Risk, Humboldt-Universität zu Berlin. Email: axel.werwatz@tu-berlin.de. Financial support from the Deutsche Forschungsgemeinschaft, SFB 649 Economic Risk, is gratefully acknowledged.
} 


\begin{abstract}
In a world with complete markets, the decision whether to rent or buy a home is not influenced by risks related to human capital. If markets are incomplete and have frictions, however, this may change. Renting should become more likely the more mobile a household has to be and the more income risk can be diversified. Using household panel data from Germany, we test both predictions. We find that mobility requirements have a positive effect on the probability of renting. This effect is robust even after controlling for state dependence, unobserved heterogeneity and other factors known to influence the tenure mode choice. Our data, however, does not support the hypothesis that potential to diversify net income risk when renting affects the tenure mode choice.
\end{abstract}

Keywords: Tenure mode choice, household mobility, background risk

JEL Classification: R21, G11, J24, C23, C25 


\section{Introduction}

Deciding whether to rent or own a home is a multifaceted and difficult choice. Early studies on the tenure mode choice centered on the relative prices of renting and owning (King, 1980; Rosen, 1979; Rosen and Rosen, 1980). Since then, many papers have focused on the role of risk for the rent or buy decision. Rosen et al (1984), for instance, found that the ratio of user cost volatility to rent volatility has a positive effect on the decision to become a renter. More recent contributions to this literature stress that it is not sufficient to consider the uncertainty of future housing cost in isolation. The impact of user cost and rent volatility may be modified by background risk that stems from household's previous investment decisions. Of particular importance is human capital, which is for most households the main source for income creation. The requirements necessary to create this income and the riskiness of the income itself may impact on the tenure mode choice.

In this paper, we analyze the importance of human capital for the tenure mode choice of German households. Previous empirical studies concentrated on the US and our paper provides comparative evidence from a market with a different institutional setting. Different to markets in several other countries, the German rental market is not exposed to rigid regulation and attractive for professional investors. This has resulted in a large private rental market that offers dwellings of quality comparable to those in the owner-occupied sector. The German housing market gives households "a free choice between a self-occupied home and renting" (Voigtländer, 2009, p. 360). In addition to providing comparative empirical evidence, we make use of household panel data, which allows us to refine some aspects of the empirical analysis.

The theoretical model of Ortalo-Magné and Rady (2002) motivates how risks related to human capital can influence the tenure mode choice. The model shows in particular that the mode choice does not depend on the risk of user cost and rents per se, but on their correlation with labor income and also on the importance of mobility requirements, both of which are related to human capital. Two conclusions 
can be drawn from the model.

First, renting a home instead of owning it exposes the household to future changes of the rent. Owning a home effectively locks housing cost at a fixed level for the period of stay and eliminates uncertainty over the future rent. This lock-in effect is more valuable the longer a household expects to stay in a region. If a household has to be mobile, on the other hand, renting shields from resale price risk and lowers the transaction cost associated with a move. Even when a household expects to move to a region where house prices are hit by the same shock, thus making resale risk less important, transactions cost will remain substantial. A mobility effect may thus arise for households in professions that require high job mobility, making renting advantageous from a risk perspective.

Second, rent uncertainty is not necessarily detrimental if it is positively correlated with the household's labor market income. In this case, renting allows the household to diversify some of its net income risk. Consider a region that is dominated by one industry: If the industry is hit by a negative shock, the incomes of those working in the industry will also experience a negative shock. This will lead to a decrease in demand for housing services and regional rents. Renters benefit from this decrease, while homeowners receive lower income, and suffer a decline in their housing wealth. Hence a diversification effect may reduce the relative risk of renting for households whose occupation is closely tied to the local economy.

Strong empirical evidence exists regarding the mobility effect, which has been the main focus of the recent empirical literature. Henderson and Ioannides (1989), for instance, use a reduced-form approach to estimate the indirect effect of variables that can be linked with mobility requirements. They state that exogenous professionrelated opportunities "may necessitate residential moves", but do not model this explicitly. Boehm (1981), Boehm et al (1991), Kan (2000), and Haurin and Gill (2002) provide evidence that mobility requirements increase the likelihood of renting. The study of Haurin and Gill (2002) is of particular interest, because it uses data of 
households from a specific profession, military men, for which the length of stay is nearly exogenous and does not have to be estimated. They find that the likelihood of owning decreases with mobility requirements. Sinai and Souleles (2005) provide empirical evidence for the US regarding the simultaneous effect of rent volatility and mobility requirements on the likelihood of renting. The less volatile the rent and the larger mobility requirements, the more likely is renting.

Less empirical evidence exists regarding the diversification effect. Davidoff (2006) finds for US data that the covariance between house prices and labor income has an effect at the intensive margin, so that households with income that is positively correlated with house prices purchase smaller houses, but finds no statistically robust effect of the diversification potential on the tenure mode choice itself.

Our study examines the empirical importance of the mobility and the diversification effect for the tenure mode choices of German households. We thereby extend the analysis beyond the US market and provide at the same time additional evidence on the importance of the diversification effect. In addition, even though our analysis is close to Davidoff (2006), we make methodological improvements by analyzing the mobility and the diversification effect together and by using the German Socio-Economic Panel (GSOEP) data set. The panel provides the necessary longitudinal information for the construction of measures of mobility requirements and the diversification potential of renting. Moreover, the panel allows us to examine the effect of these measures on the probability of renting from two perspectives, a sample of recently moved households as well as a larger sample of all households. Recent movers are closest to actually choosing their tenure mode. They are, however, also a quite specific, self-selected group of households. In the all-household sample, the panel structure allows us to take into account both the sluggish adjustments of tenure mode choice (state dependence) as well as the impact of unobservable but correlated household attitudes and preferences (unobserved heterogeneity).

Our analysis consists of two parts. First, we construct our key explanatory vari- 
ables: measures of human capital related mobility requirements and diversification potential. Mobility requirements are estimated from a survival analysis of households' residence spells. The measure of the diversification potential of renting is built on the observed correlation of profession-specific income growth and region-specific rent growth series which we construct in a preparatory step. Then we proceed to estimate the impact of these measures on the probability of renting. For the sample of recent movers, estimates are derived from a bivariate probit model that also considers the moving decision to account for selectivity. For the sample of all households, estimates are obtained from a dynamic probit model of the renting probability that accounts for unobserved heterogeneity and state dependence. We use both sets of estimates to test for the existence of the mobility effect and the diversification effect of human capital on tenure mode decisions.

A coherent set of results emerges from our analysis. The evidence on the effect of mobility requirements is statistically robust. Across all specifications and samples, we find that the propensity of renting tends to increase with mobility requirements, as theory predicts. The size of the estimated effect, however, varies considerably: our estimates imply that a decrease of the expected time of stay by six years (one standard deviation in our data) increases the probability of renting between 2 and 10 percentage points. The level of this mobility effect is about 7 percentage points in our preferred specification. Regarding the diversification effect, our measure of the correlation between profession income and regional rent series show considerable potential for such an effect. Positive correlations exist for many profession-region combinations, suggesting that the corresponding households could reduce the volatility of consumption when renting. However, we do not find any evidence for an impact of our measure of diversification potential on households' propensity to rent.

Our findings are thus in line with previous findings: while career-induced mobility requirements indeed favor renting there appears to be no noticeable diversification effect. That we are able to confirm these findings is important for several reasons. 
First, we provide fresh evidence as our study comes from a previously unconsidered market and, unlike previous articles, takes into account unobserved heterogeneity among households. Second, our analysis provides ample opportunity for both effects to come to the fore. Germany has a well-developed market for rental accommodation where the rent-or-buy decision is not tilted in favor of owning by housing consumption considerations. Moreover, we do not only consider a sample of all households but also work with a sub-sample of recent movers who were actively confronted with the tenure mode decision. Third, our result is not due to a failure of accounting for unobservable, time-constant household characteristics that are likely to affect this multifaceted decision. In our preferred specification, we control for unobserved heterogeneity and state dependence in a correlated random effects model.

The remainder of this paper is organized as follows. Section 2 provides theoretical motivation. Section 3 presents the data and explains the construction of the key variables. Our estimation strategy is explained in Section 4. Section 5 presents the empirical results. Section 6 concludes. Further details of the analysis are relegated to the Appendix.

\section{Theoretical motivation}

Ortalo-Magné and Rady (2002) is the first theoretical paper to analyze the tenure mode choice conditional on households' human capital. From this perspective, the tenure mode choice is made after the household head's human capital has been acquired early in life. Two issues follow: First, human capital will affect the tenure mode choice through the mobility required for the profession. In particular, households in a high-mobility profession will find renting a more attractive option (mobility effect). Second, the uncertain income from specialized human capital could constitute a background risk, which cannot be hedged in other markets. Households working in a profession closely linked with the local economy will receive labor income that co-moves with the regional rent. In this case, renting helps to smooth 
non-housing consumption (diversification effect).

To present these aspects more formally, we use a discrete time utility maximization framework. Dwellings are homogeneous and are supplied by absent risk neutral agents, who are prepared to act as landlords or to sell the dwellings. The rent follows

$$
R_{r, t}=R+\varepsilon_{r, t}+\sum_{k=1}^{t-1} \phi^{k} \varepsilon_{r, t-k} \quad t \geqslant 1
$$

where $r$ indicates the region, $|\phi|<1$, and $\varepsilon_{r, t}$ is white noise, possibly contemporaneously correlated between the regions. The household makes the tenure mode choice in period 0 and $R_{r, 0}=R$ in all regions. The required return rate for a housing investment is $i$ and the house price is $P=R / i$ in period 0 . A household's professional career lasts $T$ periods; a profession-related move might be necessary in $1<t^{\prime} \leqslant T$.

The household's expected utility is additive time-separable and period utility depends on housing and a composite consumption good. The direct utility contribution of housing is identical for renters and owners. The indirect contribution of housing is via the net income that can be spent on the consumption good. We assume that the household likes high expected net income, and dislikes risk, as measured by the variance of the household's net income. Based on period 0 information, the household chooses the tenure mode that provides the highest expected utility.

The net income is the gross income $Y_{t}$ minus cost of housing (rent or mortgage payments). Assuming that a home purchase requires no down-payment and that the household stays until $T$ in the home, a renter's net income is $Y_{t}-R_{r, t}$ for $1 \leqslant t<T$; an owner's net income is $Y_{t}-i P$ for $1 \leqslant t<T$ and $Y_{T}-(1+i) P+P_{r, T}$ for $t=T$. The owner thus locks in housing cost at $i P$ for all but the last period.

Conditional on period 0 information, the expected net income is $\mathrm{E}\left[Y_{t}\right]-R$ in all periods and is the same for a renter and an owner. The conditional variances, however, are different. For a renter, the conditional variance is always

$$
\operatorname{Var}\left[Y_{t}\right]+\operatorname{Var}\left[R_{r, t}\right]-2 \operatorname{Cov}\left[Y_{t}, R_{r, t}\right]
$$


For an owner, the conditional variance is either $\operatorname{Var}\left[Y_{t}\right]$ for $1 \leqslant t<T$ or $\operatorname{Var}\left[Y_{T}\right]+$ $\operatorname{Var}\left[P_{r, T}\right]+2 \operatorname{Cov}\left[Y_{T}, P_{r, T}\right]$ for $t=T$. Eq. 2 shows that if profession-specific income and rent are positively correlated, then renting diversifies income risk, and the strength of the correlation determines whether renting provides a smoother net income in periods $t<T$ than owning. The owner household is insulated from changing rent in all but the last period. Using Eq. 1, owner's net income variance for the last period $T$ becomes $\operatorname{Var}\left[Y_{T}\right]+\delta^{2} \operatorname{Var}\left[R_{r, T}\right]+2 \delta \operatorname{Cov}\left[Y_{T}, R_{r, T}\right]$ with $\delta=\phi(1+i-\phi)^{-1}$. If the rental process has no memory, $\phi=0$, then $\delta=0$ and ownership insulates the household from varying housing cost even in the last period. If rents have a memory, $\phi \neq 0$, then owners are exposed to part of the accumulated rent risk in the last period. Ceteris paribus, it is therefore more likely that a household will rent if the correlation between income and rent is high.

Some households might expect to move to another region in $1 \leqslant t^{\prime}<T$. Because the household does not have to commit in period 0 to the tenure mode that will be chosen in $t^{\prime}$, the net income volatility if renting in $t^{\prime}<t \leqslant T$ is not influenced by the current tenure mode. Without a down-payment requirement, the same holds if the household buys in the new region. The tenure mode choice in period 0 will therefore depend solely on the net income volatility of renting and owning in the current region. ${ }^{1}$ Most importantly, moving in $t^{\prime}$ induces transaction cost. Buying and selling homes have higher transactions cost than renting. ${ }^{2}$ A household that has to be mobile will presumably want to avoid these additional cost and will prefer to rent.

The framework leads therefore to two testable hypotheses: First, ceteris paribus, a household is more likely to become a renter the shorter the expected period of

\footnotetext{
${ }^{1}$ If a down-payment is required, things become more complicated, because the volatility of future direct housing cost will be influenced by the previous tenure mode. We ignore this aspect here and in the empirical application.

${ }^{2}$ In addition to cost for employing the services of real estate agents and surveyors (which in part is also incurred when renting), a purchase implies stamp duty and fees for legal transfer and mortgage underwriting.
} 
stay in the dwelling ('mobility effect'). Although owning isolates the household from rent volatility for the time of the stay, it also brings higher moving cost. This transactions cost may more than outweigh the benefit of fixed direct housing cost. Second, if renting diversifies part of the profession-specific income risk and smoothes net income, i.e., $\operatorname{Var}\left[Y_{t}-R_{t}\right]<\operatorname{Var}\left[Y_{t}\right]$, then a household should be more likely to rent ('diversification effect'). ${ }^{3}$

\section{Data and key variables}

Our main data source is the GSOEP, a representative panel survey of German households and their adult members. ${ }^{4}$ Further data comes from the Federal Statistical Office, which provides a consumer price index and city population data. The price index excludes housing services and has the year 2000 as base year. We use the index to convert nominal variables into real figures. The population numbers are combined with price data from the Ring Deutscher Makler (RDM) to compute regional house prices. ${ }^{5}$

We focus our analysis on households that (i) have a household head that is of working age (18 to 65 years), (ii) do not live in nursing and retirement homes, and (iii) live in the area of the former West Germany, as the housing market in the East is still in transition. Regarding the area, we focus our analysis on the 30 NUTS2 regions in the West of Germany. ${ }^{6}$ A NUTS2 region corresponds to a governmental

\footnotetext{
${ }^{3}$ The framework assumes stationary random variables. In the empirical analysis, we work correspondingly with growth rates.

${ }^{4}$ The data were made available to us by the German Socio-Economic Panel Study at the German Institute for Economic Research (DIW), Berlin.

${ }^{5}$ The RDM is an association of real estate professionals that publishes annual surveys on house prices in German cities. This information is based on inquiries among members and should indicate prices reasonably. We compute regional prices by aggregating data from cities in the same region, weighted with their population share.

${ }^{6}$ NUTS stands for the geocode standard Nomenclature of Units for Territorial Statistics that has been established by Eurostat to reference the administrative subdivisions of EU member countries.
} 
regional subdivision (Regierungsbezirk).

Our sample of all households defined above covers the years 1985 to 2004 and has 52,413 observations on 5,785 individual households. In addition, we use data from the 1984 survey wave to obtain lagged household information for 1985 . We extract two sub-samples from the full sample: (i) a pooled cross-section of 4,254 recent movers, that is households who have changed residence between two survey waves, and (ii) an unbalanced panel with 36,625 observations on 3,364 individual households. The sample size of the unbalanced household panel is smaller than the full sample, because our panel analysis below requires that we observe each household for at least two consecutive years, as well as the year 1984 .

\section{[Table 1 about here.]}

Column (1) in Table 1 provides summary statistics on the socio-economic characteristics of the households in the full sample. On average, 58 percent of the households in the full sample are renting; the majority do so in the private sector. This figure is in line with those reported by Kirchner (2007) for $1993 .^{7}$ The share for the US in the same year was 35 percent (Malpezzi, 1998, Table 1). In addition to different size of the rental markets in the two countries, there are also differences in the legal frameworks. Under German housing law, landlords and tenants can negotiate the rent of new contracts freely. The landlord can adjust the rent later if the market rent of comparable dwellings increases. Once agreed, the landlord can terminate the contract only under specific circumstances, such as claiming the dwelling for own use or arrears of rent, see Hubert (1998) and Tomann (1990). In the US, rents are free in most cities, but regulated in some cities, lease agreements have a fixed term and contract law varies between states. Whereas the legal framework in Germany is homogenous, it varies in the US between regions and cities. Finally, Germans seem to

\footnotetext{
${ }^{7}$ Kirchner (2007, Table 1) uses official statistics to calculate that $47.5 \%$ of all dwellings were in the private rental sector, $10.9 \%$ in the social rental sector (together $58.4 \%$ ), and $41.6 \%$ of dwellings were owner-occupied. The sectoral shares for our full panel sample are in line with these numbers and are not reported.
} 
place less value on the status of being a homeowner as such and - correspondinglydo not see renting as a stigma. Regarding owner-occupation, the settings seem similar. In both countries, imputed rents are untaxed. Mortgage interest payments are non-deductible from taxable income under German tax law, homeowners receive a subsidy on the purchase price instead. ${ }^{8}$

The socio-economic variables in Table 1 include demographic characteristics of the household head, such as age, gender, marital status, nationality (German or foreign), years of education, and household size. Economic characteristics include an indicator for households who do not report financial asset holdings (besides saving accounts), the ratio of average regional house price to yearly household income, and yearly income from employment.

\subsection{Human capital and professions}

In the first step of our analysis we establish profession groups such that members of a group have similar human capital. The sorting of households into these professions will be the basis for measuring profession-specific mobility requirements and income volatility. Standard occupation groupings are not sufficient for this task, because human capital has sizeable occupation- and industry-specific components (Kambourov and Manovskii, 2009; Neal, 1995; Poletaev and Robinson, 2008). Human capital specificity is therefore the result of an individual's occupation and the industry the individual is working in.

The GSOEP reports for each employed person both the NACE Rev.1 industry and the ISCO-88 occupation classification. We follow Shiller and Schneider (1998) and perform a cluster analysis to establish stable profession groups. Our cluster algorithm is based on the transition matrix between the industry-occupation groupings defined by 14 main NACE industries and 9 major ISCO-88 occupations. We

\footnotetext{
${ }^{8}$ Up to 1996 the subsidy was implemented through the tax code in form of accelerated depreciation rules for owner-occupied housing. From 1996-2004 homeowners received a direct payment that was based on the purchase price (or construction cost) of the house.
} 
estimate the transition probabilities using data on all household heads and spouses who have been in the GSOEP for at least two years during the period 1984 to 2004 . Appendix A.1 gives details on the cluster analysis.

[Table 2 about here.]

We obtain 14 professions that are characterized by high transition probabilities within and low transition probabilities between them, see Table A1 in Appendix A.1. ${ }^{9}$ Table 2 describes the resulting profession groups, along with short names that characterize the professions. The allocation of industries and occupations to the 14 professions largely follows intuition. For instance, professions in the health or financial industry comprise almost all ISCO-88 occupations (Occupations in Health and Social Work and Occupations in Financial Industry). Craftsmen, on the other hand, form their own profession regardless of the industry (Manual and Production Services). The sorting of households into these 14 professions is the basis for computing our two key explanatory variables, profession-specific mobility requirements and the relative risk of renting.

\subsection{Mobility requirement}

We measure the mobility requirements given the household head's profession by estimating a parametric model of residence duration. We fit the model using the information of residence spells of households in the GSOEP. With the fitted model, we then predict the expected remaining time of stay given that the household has spent already a period of time $\tau$ in the current residence. Aside from the profession of the household head and $\tau$, we also consider the effect of household characteristics on the expected remaining time of stay.

\footnotetext{
${ }^{9}$ In principle, a more finely graded grouping would be desirable to reduce bias when constructing our mobility and income measures. This, however, is precluded by the sample size of the GSOEP, particularly since we subsequently combine the professions with the regions to compute the diversification potential that a member of a profession may exploit when renting its accommodation.
} 
Let $T \geq 0$ be a continuous random variable which represents household residence stay, which is the elapsed time since a household last moved. $T$ is characterized by a parametric distribution function $F(\tau)=P(T \leq \tau)$. Using the survival function $S(\tau)=1-F(\tau)$ and the density $f(\tau)$, the expected remaining residence stay $m(\tau) \equiv$ $\mathrm{E}[T-\tau \mid T>\tau]$ is

$$
m(\tau)=\frac{1}{S(\tau)} \int_{\tau}^{\infty}(u-\tau) f(u) d u .
$$

Closed-form solutions for the integral on the right hand side of Eq. 3 exist for a number of well-known distributions (Lai and Xie, 2006, Ch. 4).

We assume that residence spells follow a lognormal distribution with possibly time-varying household covariates $\mathbf{x}(\tau)$, which implies that $\ln (\tau) \sim N\left(\mathbf{x}(\tau) \boldsymbol{\beta}, \sigma^{2}\right) .{ }^{10}$ It follows for Eq. 3

$m(\tau)= \begin{cases}\exp \left\{\mathbf{x}(\tau) \boldsymbol{\beta}+0.5 \sigma^{2}\right\} & \text { if } \tau=0 \\ \frac{1-\Phi\left(\frac{\ln (\tau)-\mathbf{x}(\tau) \boldsymbol{\beta}-\sigma^{2}}{\sigma}\right)}{1-\Phi\left(\frac{\ln (\tau)-\mathbf{x}(\tau) \boldsymbol{\beta}}{\sigma}\right)} \exp \left\{\mathbf{x}(\tau) \boldsymbol{\beta}+0.5 \sigma^{2}\right\}-\tau & \text { if } \tau>0\end{cases}$

where $\Phi(\cdot)$ denotes the standard normal distribution function. By assumption, $m(\tau)$ decreases initially and then increases monotonically with the elapsed time. Given estimates of $\boldsymbol{\beta}$ and $\sigma$, we can use Eq. 4 to impute the expected remaining time of stay given $\tau$ and the characteristics of the household. We denote the estimated expected time for a household $m_{h}$ and call the variable 'mobility requirement'. ${ }^{11}$ The smaller $m_{h}$ is, the more mobile we expect household $h$ needs to be.

[Table 3 about here.]

To estimate $\boldsymbol{\beta}$ and $\sigma$ and ultimately $m_{h}$, we run Tobit-type regressions using a flow sample of households' residence spells. Since our expected duration variable $m_{h}$

\footnotetext{
${ }^{10}$ We tried other parametric distributions, such as the exponential, log-logistic, and Weibull. The lognormal provided the best fit to the data.

${ }^{11}$ We suppress the dependence of $m_{h}$ on $\tau$ in what follows.
} 
should reflect job-related mobility requirements, we would ideally focus on moves between housing market areas, i.e., moves due to job-related reasons, and exclude moves within housing market areas, i.e., moves due to consumption needs for housing. The GSOEP provides us only with the regional NUTS2 classification, which is based on administrative areas. These areas do not necessarily coincide with housing market areas, which are difficult to establish. We therefore use all residence spells and control for other moving motives by including a rich set of explanatory variables. In particular, we regress the log of observed residence durations on a vector of household variables, such as household head's gender and age, and on marital status and household size. We also include a full set of profession dummies and an indicator for the household head's employment status in $\mathbf{x}(\tau)$ to capture professionspecific mobility differentials. Further details on the regression model and data are given in Appendix A.2.

Table 3 reports maximum likelihood (ML) estimates of the coefficients. The demographic controls are statistically significant and have the expected signs. Household mobility, for instance, decreases with household size and increases for households with unemployed heads. The estimated coefficients for the profession dummies are statistically significant in most cases. Moreover, the Wald test in Table 3 rejects the joint null hypothesis that all profession group coefficients are zero at the 5 percent level.

[Figure 1 about here.]

Figure 1 shows the estimated survival function for the least mobile profession (Profession 4: All occupations in Natural Resource Industry) and the most mobile profession (Profession 13: All occupations in Hotel, Restaurants Industry). In both cases, the function declines rather slowly, indicating that household mobility is small overall. Members of Profession 4, however, always have a lower probability of moving (conditional on already staying for time $\tau$ ) than members of Profession 13. The estimated median duration of both professions at average characteristics varies between 
5 and 7 years, see the dashed reference line at $S(\tau)=0.5$. Summary statistics of the mobility variable for the different samples are given in Table 1.

\subsection{Diversification potential of renting}

We compute 14 profession-specific income series and 30 NUTS2 region-specific rent series. Both constant-quality series are estimated from hedonic repeat-measures regressions that control for observed and unobserved characteristics of workers and dwellings, respectively (Shiller, 1993; Shiller and Schneider, 1998) ${ }^{12}$ We use these series to construct a measure of diversification potential for each of the 420 professionregion combinations.

We estimate the profession income series using the GSOEP data of individuals' employment income as the dependent variable. Including a set of time dummies for each profession allows us to construct constant-quality income index series. We convert these index series into levels by using the median profession income in each region for the year 1995, thus allowing for region-specific income level effects. ${ }^{13}$ The final income series are computed as weighted averages of the income received if employed and the benefit received if unemployed. Unemployment replacement rates are provided by the OECD; the weights are based on the actual unemployment rates of GSOEP members. We estimate the rent series using the GSOEP data on dwelling rents as the dependent variable. Including a set of time dummies for each region allows us to construct constant-quality rent index series. We convert the series into levels by using the median rent for each region in the year 1995. Appendices A.3 and A.4 provide details on the computation of the constant-quality income and rent series.

\footnotetext{
${ }^{12}$ In our panel data application, we use the fixed effects rather than the traditional repeat-sales estimator, because diagnostics of the estimated residuals indicate that the former will be more efficient.

${ }^{13}$ The income movement of a certain profession may also depend on region-specific factors. Therefore, one would ideally like to estimate constant-quality income indices for each of the 420 professionregion groups. Due to sparsity of observations, we do not estimate such indices.
} 
[Table 4 about here.]

Table 4 presents summary statistics of real income and rent growth rates for the professions and regions over the sample period and for the base year 1995. Between 1984 and 2004, the average (across and within regions) standard deviation of real rent growth rates was about 3.9 percent per year. For the same time period the average (across and within professions) standard deviation of real income growth rates was about 3.4 percent.

[Figure 2 about here.]

Not only do real rent growth rates vary among regions and real income growth rates vary across professions, they are also correlated. Figure 2 presents box plots, each box showing how income-rent covariances vary among the 30 regions for a given profession. Positive covariances correspond to the portions of the box plots right from the zero line. Several professions experience substantial positive or negative correlation of their income with the rent, depending on the region of residence. To illustrate, Managers, Professionals and Clerks are exposed to little variation over the 30 regions. The opposite is true for Occupations in Agriculture Sector.

The framework presented in Section 2 implied that a household's risk calculus will be tipped in favor of renting if the net income volatility is smaller when renting than when owning. Therefore, a volatile rent will be beneficial if it counteracts undesired variation in profession income and detrimental if it enforces such variation. To take this into account, we construct a measure of relative net income risk. We start by using the region-specific rent and the profession-specific income series and compute the real growth rate of net income. For renting, this rate is

$$
\Delta Y_{p r, t}^{R e n t}=\frac{\left(Y_{p r, t}-R_{r, t}\right)-\left(Y_{p r, t-1}-R_{r, t-1}\right)}{\left(Y_{p r, t-1}-R_{r, t-1}\right)},
$$

where $Y_{p r, t}$ is the real income level for profession $p$ in region $r$ and year $t$ and $R_{r, t}$ is 
the real rent in region $r$ and year $t$. For owning, the rate is

$$
\Delta Y_{p r, t}^{O w n}=\frac{\left(Y_{p r, t}-R_{r}\right)-\left(Y_{p r, t-1}-R_{r}\right)}{\left(Y_{p r, t-1}-R_{r}\right)},
$$

where $R_{r}$ is the corresponding within-region time average of the rent. ${ }^{14}$ The implication of Eqs. 5 and 6 is that, on average, owning and renting have the same cost, but their riskiness will differ. We measure the relative net income risk with

$$
d_{p r}=\frac{\sum_{t=1985}^{2004}\left(\Delta Y_{p r, t}^{O w n}-\Delta Y_{p r}^{O w n}\right)^{2}}{\sum_{t=1985}^{2004}\left(\Delta Y_{p r, t}^{R e n t}-\Delta Y_{p r}^{R e n t}\right)^{2}} .
$$

We call this measure 'diversification potential'. If $d_{p r}=1$, the net income volatility with locked-in user cost is exactly the same as the net income volatility if renting. If $d_{p r}>1$, renting seems more attractive from a risk perspective. Finally, $d_{p r}<1$ implies that there is no diversification potential in the local rent variation for a household of a given profession.

[Figure 3 about here.]

The scatter plot in Figure 3 shows the relationship between $d_{p r}$ and the incomerent covariance. Because $d_{p r}$ is based on net income growth rates, the association is expectedly close, but not perfect. Most points fall into the north-east and the southwest quadrants defined by the dashed reference lines at $d_{p r}=1$ and a covariance of zero. As expected, positive covariances tend to produce $d_{p r}>1$, while values of $d_{p r}$ below one tend to be associated with negative covariances. Summary statistics for $d_{p r}$ for the three different samples are given in Table 1.

The measure $d_{p r}$ has two potential limitations. First, more than one household member may earn income, resulting in opportunities for intra-household risk

\footnotetext{
${ }^{14}$ It is not possible to compute the user cost at the household level and hence at the profession group level, because important information on mortgage financing and tax treatment is not recorded in the GSOEP. The regional real user cost $R_{r}$ is then for the average household; in the empirical applications we control for the tax treatment (by using employment income as a regressor) and for changes in interest and tax rates by using time dummies.
} 
sharing. We consider such intra-household risk sharing in our empirical specifications below and replace $Y_{p r, t}$ in Eqs. 5 and 6 for double-income households with $Y_{h, t}=0.5\left\{Y_{p(H) r, t}+Y_{p(S) r, t}\right\}$. The subscripts $h$ denote the household, and $p(H)$ and $p(S)$ denote the profession of the household head and the spouse, respectively. The resulting series of net income growth, $\Delta Y_{h, t}^{j}, j \in\{$ Rent, Own $\}$, and measure of the diversification potential thus depend on the professions of both household's head and spouse. Second, $d_{p r}$ focusses exclusively on professional income, ignoring that households may have other sources of income, such as income from financial assets. The GSOEP records if a household has financial assets, but does not provide information on income from the assets. ${ }^{15}$

\section{Estimation methodology}

We present two sets of estimates of a household's conditional probability of renting: (i) a bivariate probit regression from the sample of households that moved recently, and (ii) a dynamic panel probit regression using the unbalanced household panel. We are mainly interested in the partial effects of the measure of mobility requirements, $m_{h, t}$, and the measure of diversification potential of renting, $d_{h, t}{ }^{16}$ We expect $m_{h, t}$ to have a negative and $d_{h, t}$ a positive effect, because a larger $m_{h, t}$ corresponds to smaller mobility requirements and a larger $d_{h, t}$ to a higher potential of net income risk diversification. For each regression, we estimate two specifications by adding successively more control variables. The additional variables are those that have been found in other studies to affect the tenure mode choice.

\footnotetext{
${ }^{15}$ Because the market value of the assets is not reported either, it is not possible to infer income indirectly.

${ }^{16}$ The diversification potential measure $d_{h, t}$ has a household index, as it can depend on both the household head's and the spouse's profession. The measure does not vary across households living in the same region and members working in the same profession.
} 


\subsection{Bivariate probit model for recent movers}

We first estimate the relationship between the probability to rent and our diversification and mobility measures using the sample of recent movers. These households faced the tenure mode decision recently, making them highly relevant for testing the implications of the model presented in Section 2 (Ihlanfeldt, 1981). At the same time, recent movers are a self-selected group that may differ from the population of all households in ways that could affect their tenure mode choice. As some relevant household characteristics are unobserved in our data, standard estimation methods may give biased results (Boehm et al, 1991; Kan, 2000; Painter et al, 2001).

To draw inference in the population at large, we control for selection on unobservables by employing the bivariate probit model for censored data (Van de Ven and Van Praag, 1981). In particular, we model the tenure mode choice and the moving decision with

$$
\begin{aligned}
& y_{1, h, t}=\mathbf{1}\left[\beta_{0,1}+\beta_{1} m_{h, t}+\beta_{2} d_{h, t}+\mathbf{x}_{1, h, t} \boldsymbol{\delta}_{1}+\varepsilon_{1, h, t}>0\right] \\
& y_{2, h, t}=\mathbf{1}\left[\beta_{0,2}+\mathbf{x}_{2, h, t} \boldsymbol{\delta}_{2}+\varepsilon_{2, h, t}>0\right]
\end{aligned}
$$

where $\mathbf{1}[\cdot]$ is the indicator function. Eq. 8 models the tenure mode choice: $y_{1, h, t}$ is one if household $h$ chooses to rent; otherwise it is zero. Because we observe an active tenure mode choice only when a household moves, the sample for this equation is censored. Eq. 9 models the moving decision: $y_{2, h, t}$ is one if the household moved between the previous and current survey waves; otherwise it is zero. The sample for this equation is uncensored. Assuming that $\varepsilon_{1, h, t}$ and $\varepsilon_{2, h, t}$ are independent of the regressors in both equations and that they follow a standard bivariate normal distribution with correlation $\rho$, we estimate the coefficients with ML. The estimates are then used to compute partial effects of the explanatory variables, where we evaluate the partial effects at the averages of the exogenous variables in the all household sample.

Apart from our two key explanatory variables in Eq. 8, the vector $\mathbf{x}_{1, h, t}$ considers 
additional variables that could affect the tenure mode choice. In our most extensive specification, this vector consists of socio-economic variables and a full set of time and region dummies. By including these additional regressors, we aim to control for other influences on the tenure mode choice that have received attention in the literature, such as the effects of credit constraints and differential tax treatment of owner-occupied and rental housing. Regarding credit constraints, we employ two variables: the ratio of regional house prices to yearly household income ('Priceincome ratio') and an indicator variable for households with no financial assets ('No assets'). Households with high values of the former variable and/or no financial asset holdings may have insufficient financial resources for a down-payment. Regarding tax treatment, owner occupation brings the benefit that the imputed rent is not taxed. The value of this benefit is the higher the higher household's marginal tax rate. We therefore include household head's employment income as a proxy for this potential benefit. ${ }^{17}$

The vector $\mathbf{x}_{2, h, t}$ of regressors in Eq. 9 considers the same socio-economic control variables that are also in $\mathbf{x}_{1, h, t}$. But $\mathbf{x}_{2, h, t}$ also contains profession dummies, which should capture profession-specific mobility differentials, as well as changes of household variables between survey waves, such a household size and composition, marital status, and labor force status. The profession dummmies and change variables are exclusive to $\mathbf{x}_{2, h, t}$ and are crucial for the identification of the selection coefficient $\rho .^{18}$

The bivariate probit regression in Eqs. 8 and 9 is a natural starting point for the analysis, as it considers households who have made an active tenure mode decision. The regression, however, ignores unobserved variables that may influence the tenure mode choice, such as an inherent preference for either tenure mode or household-

\footnotetext{
${ }^{17}$ The simultaneous inclusion of the two credit constraint variables makes it plausible that the income variable controls primarily for the tax advantage of ownership.

${ }^{18}$ Without exclusion restrictions the coefficients are only weakly identified due to the nonlinearities of the probit model.
} 
specific attitudes towards risk. If these unobserved variables are not independent from the regressors in Eq. 8, the estimated partial effects are generally biased. An independence assumption, however, is not very plausible. For instance, there is ample empirical evidence that risk attitudes vary with demographic characteristics, which affects the choices households make (Barsky et al, 1997; Dohmen et al, 2005).

\subsection{Dynamic panel probit model for all households}

The second regression at the household level aims to address the potential shortcoming of the analysis based on recent movers. Using the unbalanced household panel allows us to estimate the conditional probability of renting with a dynamic random effects probit regression

$$
\begin{aligned}
& P\left(y_{h, t}=1 \mid y_{h, t-1}, \ldots, y_{h, 0}, \boldsymbol{m}_{h}, \boldsymbol{d}_{h}, \mathbf{x}_{h}, c_{h}\right)= \\
& \quad \Phi\left(\beta_{0}+\beta_{1} m_{h, t}+\beta_{2} d_{h, t}+\gamma_{1} y_{h, t-1}+\mathbf{x}_{h, t} \boldsymbol{\delta}+c_{h}\right) .
\end{aligned}
$$

The variable $y_{h, t}$ is one if household $h$ is renting in period $t$; otherwise the variable is zero. The probability of renting can depend, in principle, on the entire path of all panel waves of past renting decisions $\left(y_{h, t-1}, \ldots, y_{h, 0}\right)$, past values of the observed explanatory variables (collected in the vectors $\boldsymbol{d}_{h}, \boldsymbol{m}_{h}$, and $\mathbf{x}_{h}$ ), and a householdspecific random effect $c_{h}$. The right hand side of Eq. 10 shows how the dynamic probit regression specifies the probability. As we will see below, $c_{h}$ can depend on the explanatory variables too. In addition to the variables used above, the probability of renting depends on $y_{h, t-1}$, the tenure mode in the year previous to $t$. Allowing for state dependence is important, because the adjustment of tenure modes in the general population is typically sluggish. ${ }^{19}$ The household-specific effect $c_{h}$ acknowledges that the tenure mode choice may be influenced by unobserved heterogeneity.

\footnotetext{
${ }^{19}$ Previous tenure mode status may affect current choices for several reasons. For instance, high search cost of selling and buying a home may lock homeowners in. Previous tenure mode may also be an indicator for a household's financial wealth and thus the ability to afford a home.
} 
Estimates from Eq. 10 for the effects of our key explanatory variables, $m_{h, t}$ and $d_{h, t}$, will be particularly appealing, because they apply to the tenure mode choice of all households and also allow these choices to be affected by state dependence and unobserved heterogeneity. The estimation of the regression in Eq. 10, however, faces two problems. The first is the relationship between $c_{h}$ and the observed explanatory variables, which needs to take into account that the unobserved effect is likely to be correlated with socio-economic characteristics. The second is the initial condition problem, which implies that the observed initial tenure mode choice, $y_{h, 0}$, depends most likely on the unobserved effect $c_{h}$ too (Heckman, 1981). ${ }^{20}$

We account for both problems by using the correlated random effects approach, which models the distribution of $c_{h}$ given the initial observation and the path of explanatory variables (Chamberlain, 1980; Mundlak, 1978; Wooldridge, 2005). Specifically, we assume

$$
c_{h}=\alpha_{0}+\alpha_{1} y_{h, 0}+\alpha_{2} \bar{m}_{h}+\alpha_{3} \bar{d}_{h}+\overline{\mathbf{x}}_{h} \boldsymbol{\alpha}_{4}+a_{h},
$$

which means that the unobserved effect $c_{h}$ depends on the first observed tenure mode, $y_{h, 0}$, the averages of the explanatory variables over time, and an unobserved random component, $a_{h}$. The random component is normally distributed in the population with mean zero and variance $\sigma_{a}^{2}>0$. Combining Eqs. 10 and 11 gives the correlated random effects regression for the probability of renting

$$
\begin{array}{r}
P\left(y_{h, t}=1 \mid y_{h, t-1}, \ldots, y_{h, 0}, \boldsymbol{m}_{h}, \boldsymbol{d}_{h}, \mathbf{x}_{h}, c_{h}\right)=\Phi\left(\gamma_{0}+\beta_{1} m_{h, t}+\beta_{2} d_{h, t}\right. \\
\left.+\gamma_{1} y_{h, t-1}+\mathbf{x}_{h, t} \boldsymbol{\delta}+\alpha_{1} y_{h, 0}+\alpha_{2} \bar{m}_{h}+\alpha_{3} \bar{d}_{h}+\overline{\mathbf{x}}_{h} \boldsymbol{\alpha}_{4}+a_{h}\right)
\end{array}
$$

with $\gamma_{0} \equiv \beta_{0}+\alpha_{0}$. The joint density of tenure mode choices $y_{h, 1}, \ldots, y_{h, T}$, integrated over the density of $a_{h}$, has the same structure as the conditional likelihood of the random effects probit model. The coefficients can therefore be estimated with conditional ML.

\footnotetext{
${ }^{20} \mathrm{An}$ independence assumption is only plausible if all observations for a household start with the beginning of its formation and are independent of the regressors in Eq. 10.
} 
Once the coefficients of the regression are estimated, we use

$$
\begin{aligned}
N^{-1} \sum_{h=1}^{N} \Phi & \left(\widehat{\gamma}_{a 0}+\widehat{\beta}_{a 1} \bar{m}+\widehat{\beta}_{a 2} \bar{d}+\widehat{\gamma}_{a 1} \bar{y}+\overline{\mathbf{x}} \widehat{\boldsymbol{\delta}}_{a}\right. \\
& \left.+\widehat{\alpha}_{a 1} y_{h 0}+\widehat{\alpha}_{a 2} \bar{m}_{h}+\widehat{\alpha}_{a 3} \bar{d}_{h}+\overline{\mathbf{x}}_{h} \widehat{\boldsymbol{\alpha}}_{a 4}\right)
\end{aligned}
$$

to compute average partial effects (Wooldridge, 2005). The coefficients in Eq. 13 are

the estimated coefficients of Eq. 12, divided by $\sqrt{1+\hat{\sigma}_{a}^{2}}$, where $\hat{\sigma}_{a}^{2}$ is the estimated variance of $a_{h}$. Eq. 13 is evaluated at $\bar{d}, \bar{m}, \overline{\mathbf{x}}$, and $\bar{y}$, which are the averages of the explanatory variables in the unbalanced panel of all households, see column (3) of Table 1. $N$ is the number of observations in the sample. By summing over $y_{h 0}, \bar{d}_{h}$, $\bar{m}_{h}$, and $\overline{\mathbf{x}}_{h}$, which are the explanatory variables determining $c_{h}$ according to Eq. 11, the influence of the household-specific random errors $a_{h}$ cancel each other out. The partial effects computed with Eq. 13 are therefore for the average household in the all household sample.

Using Eq. 13 gives average partial effects that account for unobserved heterogeneity and state dependence in the tenure mode choice. The estimated effects allow the unobservable effect, $c_{h}$, to be correlated with the time averages of the observations on the explanatory variables. However, this also implies that the correlation of (nearly) time-constant variables with $c_{h}$ and their effect on the probability of renting cannot be identified separately. We therefore also estimate - to obtain reference estimates - the coefficients in Eq. 10 by pooled probit. If unobserved effects play no role for households' tenure mode choices, then partial effects estimated with pooled probit will be consistent.

\subsection{Identification strategy}

Before we proceed to the empirical results, we briefly summarize our strategy to identify the effects of our key explanatory variables, the mobility requirement measure $m_{h, t}$ and the diversification potential measure $d_{h, t}$. First, we account for the complexity of tenure mode decisions by controlling for a range of other factors in our 
tenure mode equations. For transparency, we add these additional explanatory variables successively to both tenure mode models. Second, we provide for the specific features of our two estimation samples. In the sample of recent movers, the tenure mode equation is complemented by a selection equation in our bivariate probit regression to control self-selection effects in this group of households. In the panel of all households, we account for the potential state dependence of current tenure mode by including lagged tenure mode. Moreover, we exploit the panel structure of our data to control for the effects of unobserved household-specific attitudes and preferences that favor a specific tenure mode. Third, we aid identification of the mobility effect by imposing exclusion restrictions on the tenure mode models. They do not include the job-related explanatory variables (profession dummies, employment status). These variables are exclusively used in the duration regression as 'mobility shifters'. This is important as the duration regression, apart from the job-related regressors, also uses a full set of socio-economic explanatory variables to account for mobility not driven by job issues. By excluding the 'mobility shifters' from our tenure mode regressions, we ensure that the estimated effect of $m_{t, h}$ on tenure mode can be attributed properly to variation of the job-related variables (as well as $\tau$ ). This provides identification leverage and lends credibility to our interpretation of the effect of $m_{h, t}$ as stemming from job-related mobility requirements.

\section{Empirical results}

\subsection{Estimates for recent movers}

Table 1 provides in column (2) summary statistics for the sample of 4,254 recent movers. Recent movers are different from the general population, as represented by the full sample summarized in column (1). The socio-economic characteristics suggest that recent movers are in the early stage of their life-cycle. On average, they are younger, earn less income, have accumulated less assets, live in smaller 
households, and comprise less families with less children. Moreover, a recent mover is also more likely to be a renter.

We use the bivariate probit regression of Eqs. 8 and 9 to analyze the tenure mode choice of recent movers. The coefficients of this model are estimated with ML. Partial effects for the tenure choice equation are computed at the sample averages of the explanatory variables for the full sample, see column (1) of Table 1.

\section{[Table 5 about here.]}

Table 5 reports the estimation results. Standard errors are computed with the bootstrap, because $m_{h, t}$ and $d_{h, t}$ are generated regressors (Efron and Tibshirani, 1993). ${ }^{21}$ We present two specifications of the tenure choice equation. In Specification 1 , only our key explanatory variables and a set of time dummies and region dummies are included. In Specification 2, additional socio-economic variables are added. The selection equation contains the same set of regressors in both specifications.

Before examining the estimated partial effects of the tenure choice equation, we discuss the results for the moving decision. The magnitude of the estimated coefficients of Eq. 9 are very similar in both specifications. Moreover, most of the coefficients are statistically significant and have reasonable signs. Household size and age, for instance, have a negative effect on the propensity to move. Changes in the composition of the household, marital status, and labor force participation, on the other hand, increase the likelihood of changing residence. In both specifications, a likelihood ratio test rejects the null hypothesis that the correlation, $\rho$, is zero at the usual significance levels. ${ }^{22}$ Estimating Eq. 8 independently will therefore give biased estimates for the population coefficients when using the sample of recent movers.

\footnotetext{
${ }^{21}$ We obtain bootstrap standard errors that take into account clustering of the observations over individual households. For each cluster, we resample from the original set until the new set has as many clusters as the original set. We repeat this procedure 200 times. For each full sample replication, we estimate, both, coefficients and partial effects and use the standard deviations across the replications as bootstrap standard errors.

${ }^{22}$ The estimated correlation between the error terms is negative. A priori one would expect that
} 
Turning to the tenure mode choice equation, the effect of an increase of household's mobility requirement — which corresponds to a decrease of $m_{h, t}$ - on the probability of renting is positive and statistically significant at the usual levels in Specification 1. In Specification 2 the p-value of the null hypothesis that the partial effect equals zero is 0.159. Considering the estimated partial effect in Specification 1, a decrease of the expected time of stay by six years (i.e. a decrease by one standard deviation) yields an increase of the probability of renting by 6 percentage points. There is, however, a very pronounced drop in the estimated magnitude of this effect in Specification 2. In particular, the point estimate of the partial effect is reduced to a level of 2 percentage points for the same decrease of the expected time of stay. This drop is attributable to the inclusion of variables that are directly linked to $m_{h, t}$, such as profession or household size. This leaves little independent variation left in $m_{h, t}$ for the sample of recent movers. ${ }^{23}$ Identification of the mobility effect is thus severely hindered in Specification 2.

Regarding the other key explanatory variable, the likelihood of renting should be higher for households in profession-region cells where the regional rent volatility offers the potential to diversify some of the net income variation. Yet, in both specifications the estimated partial effects of the diversification potential $d_{h r, t}$ is indistinguishable from zero. Our data for recent movers does not support the notion that households exploit the diversification potential of renting when making their tenure mode choice.

The estimated partial effects of the control variables in Specifications 2 in Table 5 have plausible signs and magnitudes. In particular, the variables that proxy the presence of credit constraints ('Price-income ratio' and 'No assets') and the differential tax treatment of owner-occupied and rental housing ('Employment income') unobserved factors which increase households' mobility should also increase their likelihood to rent. However, one must bear in mind that Eqs. 8 and 9 are reduced-form equations which makes any interpretation of the estimated correlations difficult.

${ }^{23}$ For recent movers, $m_{h, t}$ is almost always evaluated at $\tau=0$. As some households are not always interviewed in the same months, residence spells for recent movers can be greater than zero. 
have the expected signs and are statistically significant. Credit constraints increase while tax benefits for higher income households decrease the probability to rent. Notably, socio-demographic characteristics that can be linked to $m_{h, t}$, such as 'Age' and 'Children' have no statistically significant effect on the tenure mode choice. This confirms the findings in Boehm (1981), Henderson and Ioannides (1989), and Kan (2000) that these variables mainly proxy households' mobility requirements.

In summary, the evidence in Table 5 points to a positive mobility effect. Households with higher profession-specific mobility demands have a greater likelihood to rent their accommodation, even after including a full set of controls. The positive diversification effect suggested by the recent literature is not found in our sample of recent movers.

\subsection{Estimates for all households}

We now turn to the analysis of the tenure mode choice using the unbalanced household panel. Summary statistics for this sample are reported in column (3) in Table 1. Compared to the general population (as summarized by the full sample in column (1) in Table 1) households in the unbalanced panel are quite similar with respect to most of their socioeconomic characteristics. Due to panel attrition of more mobile households, households in the unbalanced panel are, on average, older and have longer expected remaining stays. Moreover, they are more likely to own their home.

We estimate the dynamic probit model of Eq. 10, both, as a pooled probit regression and as correlated random effects regression, see Eq. 12. While the former ignores the unobserved household-specific term $c_{h}$, the latter allows it to be correlated with time-averages of the observed household characteristics. We estimate each of the two regressions with two specifications. The first specification includes the measures of mobility requirements and diversification potential, the initial and lagged tenure mode, and time and region dummies as explanatory variables. The second specification adds further socio-economic control variables. The correlated 
random effects estimates further include a set of dummy variables taking the value one if a household is not observed in a given year. These dummies control for systematic sample attrition that might be correlated with $c_{h}$. The standard errors of the corresponding average partial effects are estimated with a block bootstrap. ${ }^{24}$

\section{[Table 6 about here.]}

The partial effects estimated with the pooled probit regression ignore unobserved heterogeneity among households and act as a reference. These effects are reported in columns (1) and (2) of Table 6. The partial effects imply very strong inertia in the tenure mode choice. The estimated positive effect of $y_{h, t-1}$ exceeds 0.94 in all specifications. This implies that having been a renter in the previous period makes renting in the current period very likely. Regarding our key explanatory variables $m_{h, t}$ and $d_{h, t}$, the pooled probit estimates are qualitatively comparable to the earlier estimates using the sample of recent movers. The estimated effect of $m_{h, t}$ is negative and significant in both specifications, whereas the effect of $d_{h, t}$ is statistically insignificant. The magnitude of mobility effect implies that a decrease of the expected time of stay by six years - and therefore an increase in the mobility requirement - leads to an increase of the probability of renting by between 8 to 10 percentage points.

The results from our preferred approach, which is the correlated random effects regression, are reported in columns (3) and (4) of Table 6. Before examining the estimated average partial effects, we discuss the evidence on the importance of unobserved household-specific effects for the tenure mode choice. This evidence is

\footnotetext{
${ }^{24}$ Each block consist of all observations for an household. For each set of blocks with the same size (measured in years), we resample from the original set until the new set has as many blocks as the original set. We repeat this procedure 200 times. This sampling procedure preserves the total sample size as well as the pattern of unbalancedness found in the full sample. For each full sample replication, we estimate average partial effects and use the standard deviations across the replications as bootstrap standard errors.
} 
provided by the estimated standard deviation of the unobserved effect in Eq. 12, reported in the lowest panel of columns (3) and (4). In each of the two specifications of the correlated random effects regression, the estimate of $\sigma_{a}$ is substantial. The likelihood ratio test of the hypothesis that $\theta \equiv \sigma_{a}^{2} /\left(1+\sigma_{a}^{2}\right)$ is zero is always rejected. ${ }^{25}$ Furthermore, controlling for unobserved effects improves the fit of the model, as evidenced by the change in the log likelihood. It follows from this evidence that pooled probit estimates - even if socioeconomic differences between households are considered as in Specification 2-will be biased and inconsistent.

The average partial effects estimated with Eq. 13 take unobserved heterogeneity explicitly into account. These effects are reported in columns (3) and (4) of Table 6. The estimated average partial effect of the lagged tenure mode, $y_{h, t-1}$, is positive and significant in both specifications of the correlated random effects regression. Changing the tenure mode from owner to renter increases a household's probability of renting in the following year by approximately 50 to 57 percentage points. The magnitude of the average partial effects are substantially smaller than the biased estimates from the pooled probit regression.

The correlated random effects model strengthens the evidence for the effect of mobility requirements on the probability of renting. The estimated average partial effect of $m_{h, t}$ is negative and significant in both specifications. An decrease of the expected time of stay by six years increases the probability of renting by 7 to 8 percentage points. Hence, even in the presence of state dependence, unobserved heterogeneity, and several other control variables, the effect of mobility requirements is present. However, there is no evidence on the diversification effect. Though the estimated average partial effect of $d_{h, t}$ is positive in columns (3) and (4), it is always statistically insignificant. The estimates from the panel of all households thus confirm the earlier findings obtained for recent movers.

\footnotetext{
${ }^{25}$ Since the variance of the idiosyncratic error in the underlying latent variable model is one, $\theta$ measures the relative importance of $\sigma_{a}^{2}$. If $\theta$ is zero, there is no unobserved effect and the pooled probit and the random effect regressions are identical.
} 
The estimated average partial effects of the socio-economic control variables in columns (3) and (4) in Table 6 are reasonable. Again variables associated with mobility requirements of a household are statistically insignificant. The estimated magnitudes of the average partial effects, however, differ from the pooled probit estimates in columns (1) and (2) in Table 6 and those obtained for recent movers, see Table 5. This bias can be motivated with the importance of the unobserved household-specific effect, which is ignored in the latter regressions.

\section{Conclusion}

From a risk perspective, owning appears more attractive than renting since it shields households from regional rent volatility. Recent contributions to the literature, however, have pointed out two potential risk-limiting effects of renting: a mobility effect and a diversification effect. Both effects come into focus when the tenure mode choice is viewed conditional on a household's human capital. The mobility effect should matter for households faced with substantial mobility requirements. For them, renting may be the more attractive tenure mode as it avoids the resale price risk and high transaction cost owners face if they change residence. The diversification effect should matter for households whose human capital is vested in a profession closely related to the local economy. For such households, local rent fluctuations tend to match and counterbalance professional income fluctuations and smooth non-housing consumption.

This paper presents an empirical test of both human capital related effects on the tenure mode choice of German households. The first part of our analysis concerns the measurement of both effects. Our measure of mobility requirements - the estimated expected time of stay - shows substantial variation across households. Our measure of the diversification potential reflects the co-movement of profession-specific incomes and region-specific rents. Moreover, variation in this measure across professionregion cells is considerable. 
The second part of our analysis concerns testing if these measures can explain observed tenure mode choices. Our evidence comes from two sets of estimates, one for households who have recently moved and two for an unbalanced panel of all households. Evidence on the mobility effect is unambiguous: a shorter expected time of stay increases the propensity to rent. This holds even after controlling for state dependence and unobserved heterogeneity in a dynamic panel probit model estimated from the sample of all households. The presence of a diversification effect, on the other hand, cannot be found in our data. According to theory, the probability of renting should increase with our measure of this effect. The estimated effect, however, is indistinguishable from zero in all of our empirical specifications.

The empirical findings of our study are particulary interesting with respect to a household's risk management opportunities. A well-functioning private rental market - as in Germany - allows households to separate housing consumption from housing investment and thus provides valuable flexibility. This is important for households with high mobility requirements. The results of our study indicate that these households exploit the lower effective cost of renting. Moreover, from a theoretical perspective, renting can provide further benefits by allowing smoothing non-housing consumption. The empirical results of our study, however, provide no evidence that households exploit this diversification potential.

\section{Acknowledgements}

We have benefited from comments on earlier versions of this paper by five anonymous referees, Bernd Fitzenberger, James Follain, Christian Hilber, Franz Hubert, Verity Watson and participants at presentations at the AREUEA Annual Conference 2009, ERES Annual Conference 2008, Regensburg Conference on Real Estate Economics and Finance 2007, University of Aberdeen, DIW Berlin, Heriot Watt University Edinburgh, Humboldt-Universität zu Berlin, Universität Hannover, and Universität Tübingen. The usual disclaimer applies. 


\section{A Appendix}

\section{A.1 Cluster analysis}

Our cluster analysis uses the observed transitions between occupation-industry groups to delineate professions. Let $i$ denote a occupation-industry group and $p_{i j}$ the probability of an individual belonging to this group conditional on being a member of group $j$ in the previous period. The transition probability is

$$
p_{i j}=\frac{\sum_{t \in T} N_{i, t \mid j, t-1}}{\sum_{t \in T} N_{i, t}},
$$

where $N_{i, t \mid j, t-1}$ is the number of individuals in group $i$ in period $t$ conditional on being in group $j$ in period $t-1 . N_{i, t}$ denotes the total number of individuals in group $i$ in period $t$.

To estimate transition probabilities between occupation-industry groups, we use information on individuals in the full sample that are in employment and have been in the GSOEP for at least two years. Each individual falls into one of 9 ISCO-88 1-digit occupations and one of 14 NACE Rev.1 1-digit industries. This leads to 126 occupation-industry groups, of which two have no observations in our sample. The estimated transition probabilities provide the data with which we select professions. We use a K-Medians cluster algorithm that starts from a given partition of the groups and proceeds by exchanging groups between clusters so that all groups within a cluster are closest to the cluster's centroid. The algorithm converges when occupation-industry groups are no longer exchanged between profession groups. We run the cluster analysis with different initial profession groupings found by a first step agglomerative cluster algorithm. In most case, the cluster analysis leads to 14 profession groups.

[Table A1 about here.]

Table A1 presents the estimated transition matrix for the 14 professions. The professions are fairly stable. The diagonal elements of the matrix shows the tran- 
sition probabilities within professions. The lowest within transition probability is 79 percent, the highest 94 percent. The off-diagonal elements, which are the transition probabilities between professions, are almost always lower than 3 percent. The lowest between transition probability is 0 percent and the highest about 10 percent.

\section{A.2 Survival analysis}

We estimate the coefficients in Eq. 4 using a linear regression for censored data

$$
\ln \left(\tau_{h}\right)=\mathbf{x}\left(\tau_{h}\right) \boldsymbol{\beta}+\varepsilon_{h},
$$

where $\tau_{h}$ is the time since household $h$ moved into the current dwelling. A spell is completed if the household moves to a new residence or disbands. Disbandment is the result of emigration or death. Incomplete spells are defined to be right-censored. The vector $\mathbf{x}\left(\tau_{h}\right)$ collects, possibly time-varying, household characteristics at time $\tau_{h}$, as well as full set of profession, region, and time dummies. The latter take the value one for if the household' residence spells begins in the respective year. The idiosyncratic error term is distributed with $\varepsilon_{h} \sim N\left(0, \sigma^{2}\right)$.

Eq. A2 is estimated with ML, using a flow sample of residence spells from the GSOEP. In particular, a household enters the sample if it moves to a new residence or is newly formed between 1985-2003. We allow for multiple spells of the same household and adjust standard errors in the estimation accordingly. In total, we have 6,842 residence spells, of which 3,407 are completed. The remaining spells are right-censored.

[Table A2 about here.]

Table A2 reports summary statistics of household characteristics in the spell sample. With respect to most of their socioeconomic characteristics households in this sample are quite similar to recent movers as summarized in column (2) of Table 1 . This is attributable to the fact that the GSOEP, on average, follows newly moved households for only 5 years. 


\section{A.3 Income series}

We derive the profession-specific constant-quality income series from the hedonic repeat-measures regression

$$
y_{i, t}=\alpha_{0}+\mathbf{x}_{i, t} \boldsymbol{\beta}+\gamma_{p 0} D_{p, i, 0}+\gamma_{p t} D_{p, i, t}+c_{i}+\varepsilon_{i, t},
$$

where $y_{i, t}$ is the $\log$ of the employment income of individual $i$ in period $t$ ( $t=$ $1984, \ldots, 2004)$. The vector $\mathbf{x}_{i, t}$ contains time-varying individual characteristics, as well as a full set of region dummies. The binary indicator $D_{p, i, 0}$ is set to one if individual $i$ is employed in profession $p$ in the base period $t=1995$. The binary indicator $D_{p, i, t}$ is set to one if individual $i$ is employed in profession $p$ in period $t \neq 1995$. The profession dummies for the base period, $D_{p, i, 0}$, control for the income change of individuals who switch professions between periods. Observed and unobserved time-constant characteristics are captured by the individual specific effect $c_{i}$. $\varepsilon_{i, t}$ is an idiosyncratic error term.

Estimating Eq. A3 directly would lead to a biased estimator, because unobserved characteristics captured in $c_{i}$ are omitted. We therefore use a fixed effects estimator, which subtracts the individual-specific average from each observed variable. This removes the observed and unobserved time-constant characteristics, $c_{i}$, from the regression equation. Estimating this modified regression with OLS leads to an unbiased estimator for the coefficients in Eq. A3.

We use an unbalanced panel sample of the relevant 15,701 employed individuals in the GSOEP to estimate the coefficients. Following the literature on Mincer wage equations we include education in years, labor force experience in years, and labor force experience squared in $\mathbf{x}_{i, t}$. Further controls comprise age, work hours, and duration of current employment. These variables are suggested by Shiller and Schneider (1998) to ensure that the income index captures only the income trend of fully employed individuals in a given profession. As economic theory does not suggest a particular functional form for the age and work hours variable, we use the 
Box-Cox type transformation suggested in Bunke et al (1999). These functions capture non-linearities, such as the common hump-shaped age profile of income. Table A3 presents these fixed effects estimates. The fit of the regression is reasonably good as measured by the $R^{2}$. Moreover, the estimated coefficients of the control variables have reasonable signs and are statistically significant.

[Table A3 about here.]

We obtain profession-specific income series in two steps. First, we compute constant-quality index series $I_{p, t}=\exp \left\{\widehat{\gamma}_{p, t}-0.5 \widehat{\sigma}_{\gamma_{p, t}}^{2}\right\} . \widehat{\gamma}_{p, t}$ is the estimated time dummy coefficient from Eq. A3 for profession $p$ in period $t . \widehat{\sigma}_{\gamma_{p, t}}^{2}$ is the estimated variance of the coefficient estimator, which corrects for small-sample bias. The index series are normalized to one in the base period 1995. Second, we convert the series into series in levels, thereby taking account for unemployment

$$
Y_{p r, t}=\left(1-u_{p, t}\right) I_{p, t} \bar{Y}_{p r}+u_{p, t} B_{t} I_{p, t} \bar{Y}_{p r}
$$

The median employment income $\bar{Y}_{p r}$ is for profession-region cell $(p r)$ in year 1995 . The unemployment rate $u_{p, t}$ is estimated from the GSOEP. $B_{t}$ is the OECD summary measure of unemployment benefits, which is the ratio of gross benefit entitlements and gross earnings (Martin, 1996). $B_{t}$ is published only on a biannual basis and we interpolate values for non-covered years linearly. The full-employment income $I_{p, t} Y_{p r, 1995}$ and the unemployment benefit $I_{p, t} B_{t} Y_{p r, 1995}$ are weighted by the profession-specific unemployment rate in the respective period. After deflating with the consumer price index, we obtain the final constant-quality real income series.

\section{A.4 Rent series}

We derive the region-specific rent series from the hedonic repeat-measures regression

$$
y_{i, t}=\alpha_{0}+\mathbf{x}_{i, t} \boldsymbol{\beta}+\gamma_{r, t} D_{r, i, t}+c_{i}+\varepsilon_{i, t},
$$


where $y_{i, t}$ is the $\log$ rent of dwelling $i$ in period $t(t=1984, \ldots, 2004)$. The vector $\mathbf{x}_{i, t}$ collects time-varying characteristics of the dwelling. These include variables related to modernization (indicators if a bathroom and central heating are present), as well as variables related to the landlord-tenant relationship (indicators for subsidized rental housing and different lengths of tenancy). The binary indicator $D_{r, i, t}$ is set to one if the dwelling is observed in region $r$ and period $t$. Unobserved and observed time-constant characteristics, such as size of the dwelling, type of building, and type of urban area are captured by the dwelling-specific effect $c_{i} . \varepsilon_{i, t}$ is an idiosyncratic error term.

We estimate the coefficients in Eq. A5 using an unbalanced panel sample of 9,852 rental dwellings in the GSOEP. As before, we use a fixed effects estimator, which removes the time-constant observed and unobserved characteristics, $c_{i}$, from the regression. Table A4 reports the coefficient estimates. The fit of the regression measured with the $R^{2}$ is reasonably good. Moreover, the estimated coefficients for the included time-varying variables have reasonable signs and are statistically significant at the usual significance levels.

[Table A4 about here.]

We compute region-specific constant-quality rent series in two steps. First, we compute constant-quality index series from the estimated time dummy coefficients in Eq. A5 with $I_{r, t}=\exp \left\{\widehat{\gamma}_{r, t}-0.5 \widehat{\sigma}_{\gamma_{r, t}}^{2}\right\}$, where $\widehat{\gamma}_{r, t}$ is the estimated time dummy coefficient for region $r$ in period $t . \widehat{\sigma}_{\gamma_{r, t}}$ is the corresponding estimated standard error of the coefficient estimator. This second term corrects for small sample bias. The index series are normalized to one for our base period 1995. We then, second, convert the index series into level series $R_{r, t}=\widehat{I}_{r, t} \bar{R}_{r, 1995}$, where $\bar{R}_{r, 1995}$ represents the median rent level in region $r$ for the year 1995. After deflating with the consumer price index, we obtain the final constant-quality real rent series. 


\section{References}

Arellano M (1987) Computing robust standard errors for within-groups estimators. Oxford Bulletin of Economics and Statistics 49:431-434

Barsky RB, Juster FT, Kimball MS, Shapiro MD (1997) Preference parameters and behavioral heterogeneity: An experimental approach in the health and retirement study. Quarterly Journal of Economics 112:537-579

Boehm TP (1981) Tenure choice and expected mobility: A synthesis. Journal of Urban Economics 10:375-389

Boehm TP, Herzog HW, Schlottmann AM (1991) Intra-urban mobility, migration, and tenure choice. The Review of Economics and Statistics 73:59-68

Bunke O, Droge B, Polzehl J (1999) Model selection, transformations and variance estimation in nonlinear regression. Statistics 33:197-240

Chamberlain G (1980) Analysis of covariance with qualitative data. The Review of Economic Studies 47:225-238

Davidoff T (2006) Labor income, housing prices, and homeownership. Journal of Urban Economics 59:209-235

Dohmen T, Falk D, Huffmann U, Sunde U, Schupp J, Wagner W (2005) Individual risk attiudes. new evidence from a large, representative, experimentally-validated survey. DIW Discussion Paper 511, German Institute for Economic Research, Berlin

Efron B, Tibshirani RJ (1993) An Introduction to the Bootstrap. Chapman and Hall, New York

Haurin DL, Gill HD (2002) The impact of transaction costs and the expected length of stay on home ownership. Journal of Urban Economics 51:563-584 
Heckman JJ (1981) The incidental parameters problem and the problem of initial conditions in estimating a discrete- time-discrete data stochastic process. In: Manski C, McFadden D (eds) Structural Analysis of Discrete Data with Econometric Applications, MIT Press, Cambridge

Henderson JV, Ioannides YM (1989) Dynamic aspects of consumer decisions in housing markets. Journal of Urban Economics 26:212-230

Hubert F (1998) Private rented housing in Germany. Netherlands Journal of Housing and the Built Environment 13:205-232

Ihlanfeldt KR (1981) An empirical investigation of alternative approaches to estimating the equilibrium demand for housing. Journal of Urban Economics 9:97-105

Kambourov G, Manovskii I (2009) Occupational specificity of human capital. International Economic Review 50:63-115

Kan K (2000) Dynamic modeling of housing tenure choice. Journal of Urban Economics 48:46-69

King MA (1980) An econometric model of tenure choice and demand for housing as a joint decision. Journal of Public Economics 14:137-159

Kirchner J (2007) The declining social rental sector in Germany. European Journal of Housing Policy 7:85-101

Lai CD, Xie M (2006) Stochastic ageing and dependence for reliability. Springer, New York

Malpezzi S (1998) Private rented housing markets in the United States. Netherlands Journal of Housing and the Built Environment 13:353-386

Martin JP (1996) Measure of replacement rates for the purpose of international comparison: A note. OECD Economic Studies 26:99-115 
Mundlak Y (1978) On the pooling of time series and cross section data. Econometrica $46: 69-85$

Neal D (1995) Industry-specific human capital: Evidence from displaced workers. Journal of Labor Economics 13:653-677

Ortalo-Magné F, Rady S (2002) Tenure choice and the riskiness of non-housing consumption. Journal of Housing Economics 11:266-279

Painter G, Gabriel S, Myers D (2001) Race, immigrant status, and housing tenure choice. Journal of Urban Economics 49:150-167

Poletaev M, Robinson C (2008) Human capital specificity: Evidence from the dictionary of occupational titles and displaced worker surveys. Journal of Labor Economics $26: 387-420$

Rosen HS (1979) Housing decisions and the U.S. income tax. Journal of Public Economics 11:1-23

Rosen HS, Rosen KT (1980) Federal taxes and homeownership: Evidence from time series. Journal of Political Economy 88:59-75

Rosen HS, Rosen KT, Holtz-Eakin D (1984) Housing tenure, uncertainty, and taxation. Review of Economics and Statistics 66:405-416

Shiller RJ (1993) Macro Markets. Creating Institutions for Managing Society's Largest Economic Risks. Clarendon Press, Oxford

Shiller RJ, Schneider R (1998) Labor income indices designed for use in contracts promoting income risk management. Review of Income and Wealth 44:163-82

Sinai T, Souleles NS (2005) Owner-occupied housing as a hedge against rent risk. The Quarterly Journal of Economics 120:763-789

Tomann H (1990) The housing market, housing finance and housing policy in West Germany: Prospects for the 1990s. Urban Studies 27:919-930 
Van de Ven WPMM, Van Praag BMS (1981) The demand for deductibles in private health insurance: A probit model with sample selection. Journal of Econometrics $17: 229-252$

Voigtländer M (2009) Why is the German homoeownership rate so low? Housing Studies 24:355-372

Wooldridge JM (2005) Simple solutions to the initial conditions problem in dynamic, nonlinear panel data models with unobserved heterogeneity. Journal of Applied Econometrics 20:39-54 


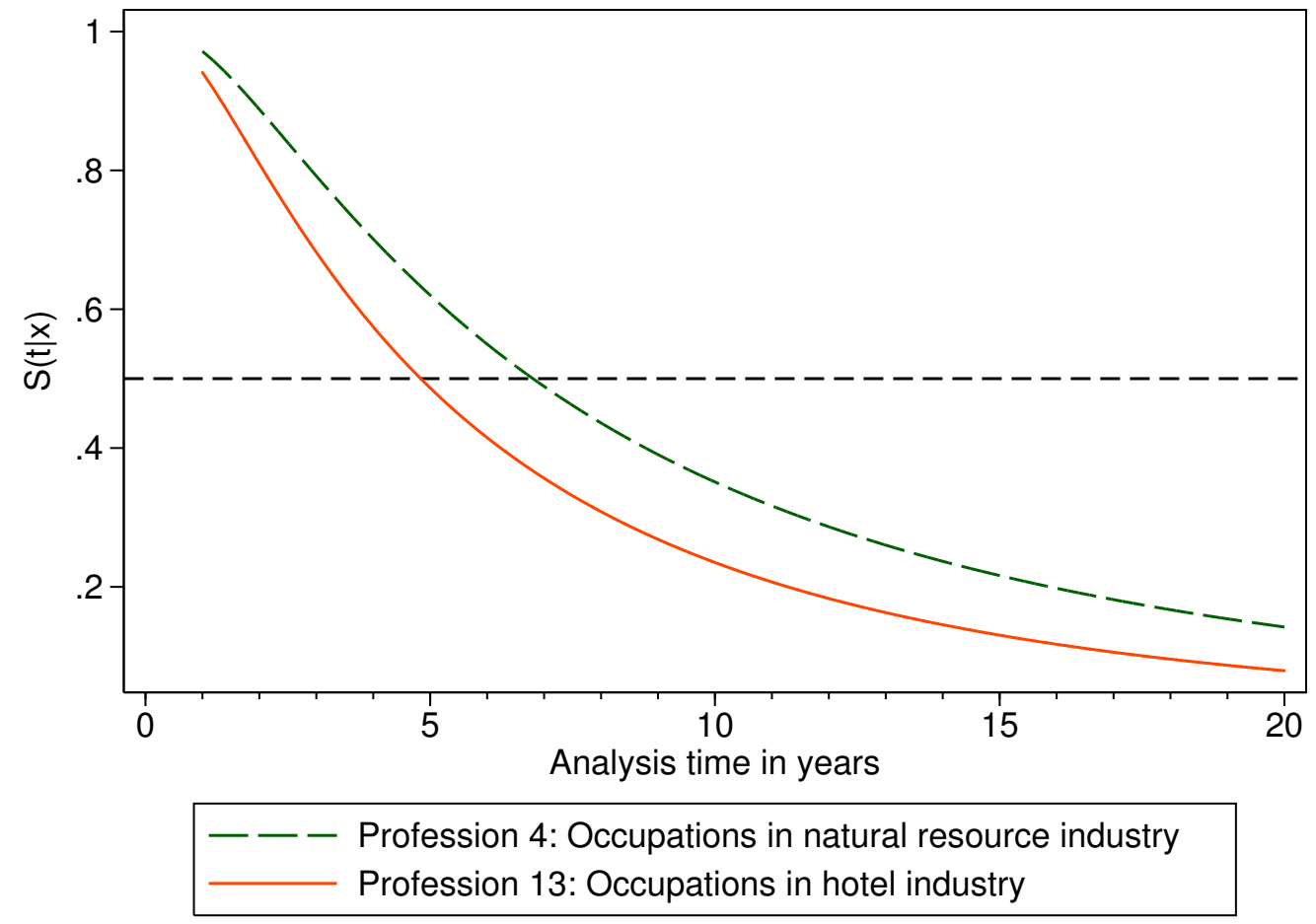

Figure 1: Estimated survival functions for least mobile ('Profession 4') and most mobile profession ('Profession 13'). Estimated with a lognormal regression of residence spells. Survival function $S(\tau \mid \mathbf{x})$ is evaluated at sample averages of household characteristics at beginning of residence spell. 


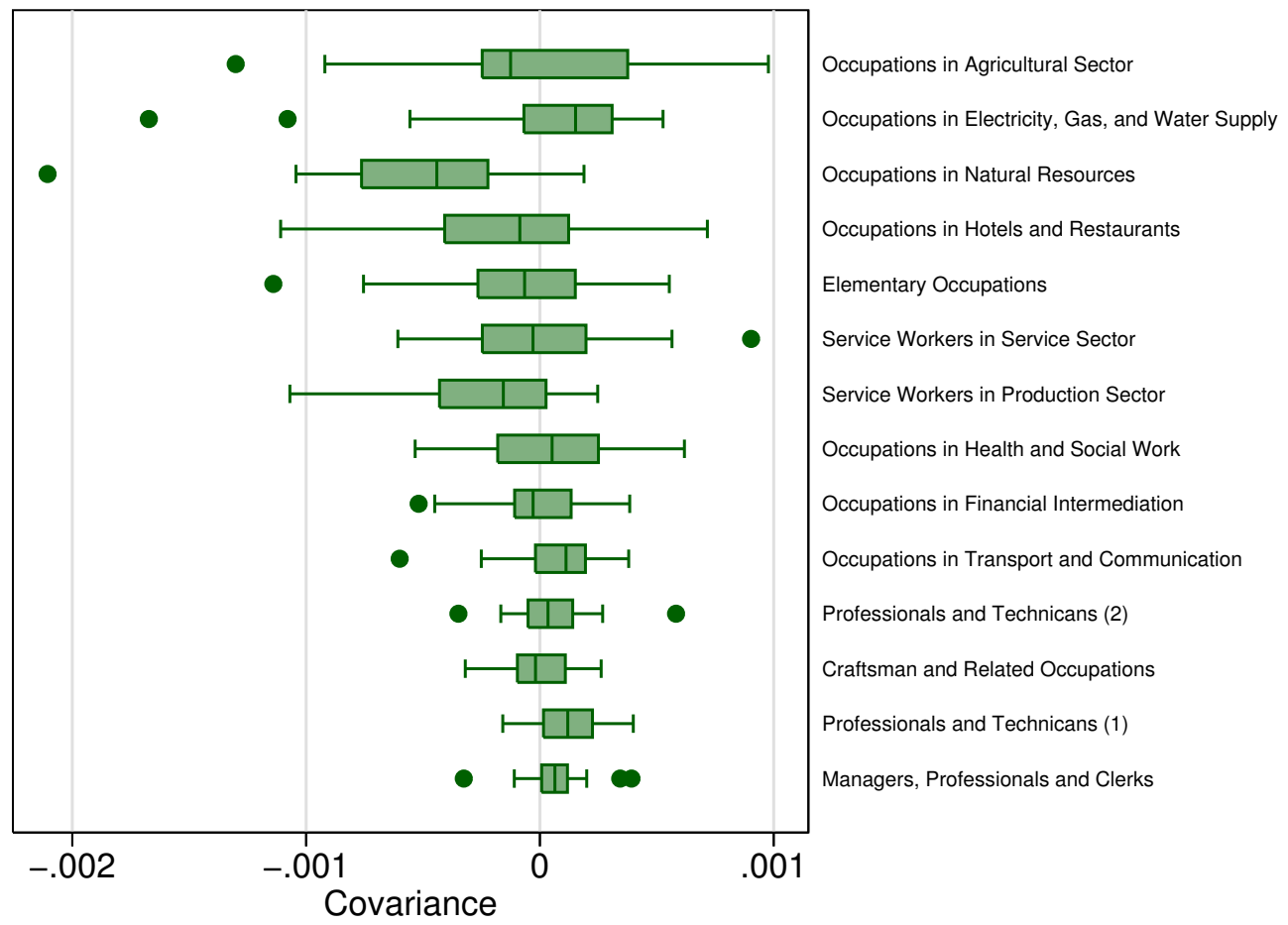

Figure 2: Box plots of covariances between rent and income growth rates. Box plots are for the 14 professions and are presented with the names describing these professions. 


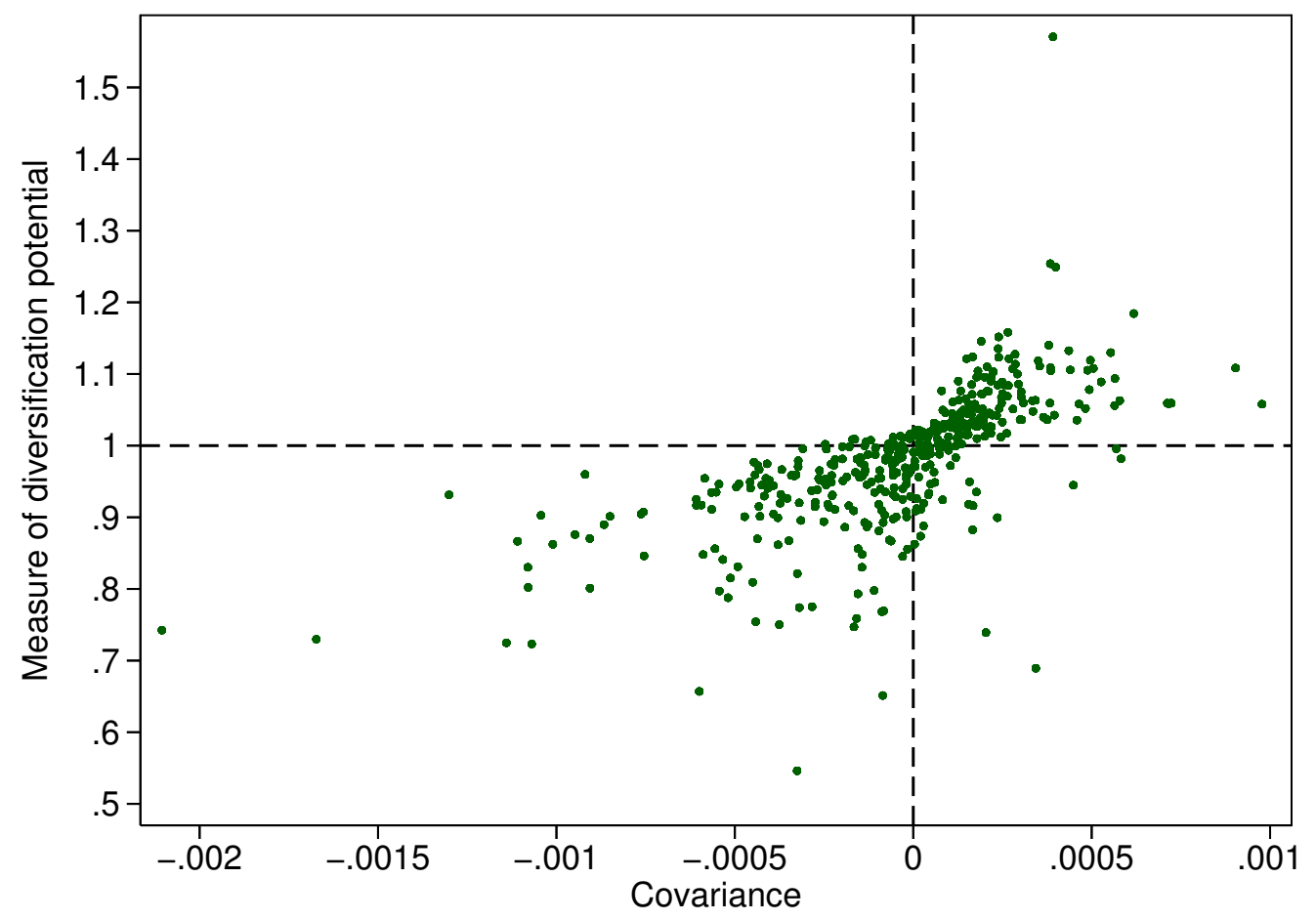

Figure 3: Scatter plot of diversification potential and covariance. Shows the empirical relationship between the measure of diversification potential, $d_{p r}$, and the covariance between rent and income growth rates for the 420 profession-region cells. 
Table 1: Summary statistics by household sample for the years 1985-2004. Averages of variables, standard deviations of the variables are in square brackets. Employment income is yearly income from employment of household head in real (year 2000) Euros. Price-income ratio is the ratio of the average price of a single-family dwelling of average quality with yearly household income. Data for regional house prices are provided by the RDM. Diversification potential is calculated according to Eq. 7. This variable is allowed to depend on both the profession of the household head and the spouse. Mobility requirement is the expected remaining time of stay in years, as defined in Eq. 4.

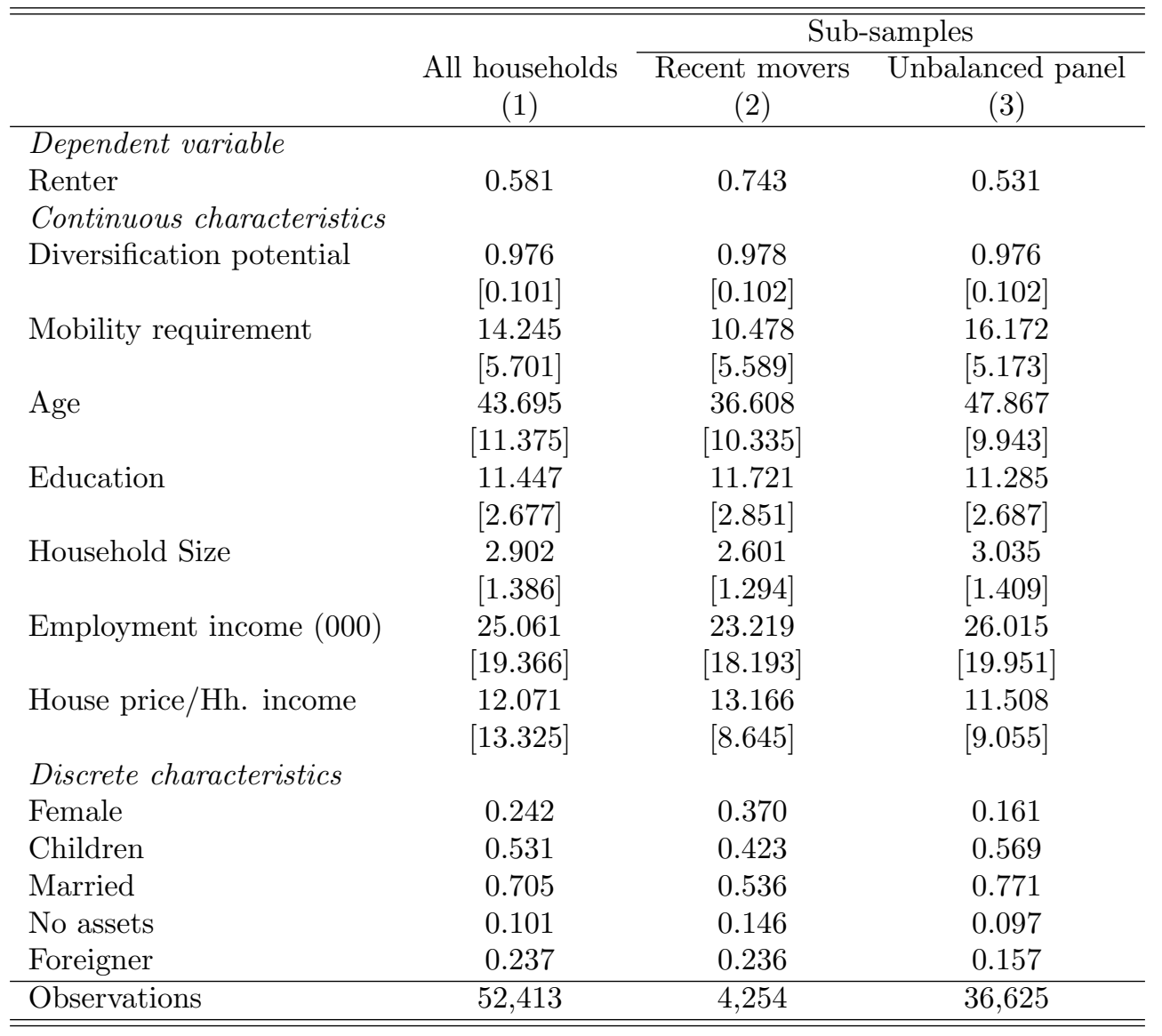


Table 2: Clustering of industries and occupations into professions. Occupations are the 9 main occupations according to ISCO- 88 classification, which comprises the following occupations: ISCO 1 Legislators, senior officials, and managers, ISCO 2 Professionals, ISCO 3 Technicians and associate professionals, ISCO 4 Clerks, ISCO 5 Service workers and shop and market sales workers, ISCO 6 Skilled agricultural and fishery worker, ISCO $7 \mathrm{Craft}$ and related trades workers, ISCO 8 Plant and machine operators and assemblers, ISCO 9 Elementary occupations. Industries are the 14 main sectors according to NACE, Rev. 1.1 classification, which comprises the following sectors: NACE A Agriculture, hunting, and forestry, $N A C E C$ Mining and quarrying, $N A C E D$ Manufacturing, $N A C E E$ Electricity, gas and water supply, NACE F Construction, NACE G Wholesale and retail trade, NACE H Hotels and restaurants, NACE I Transport, storage and communication, NACE J Financial intermediation, NACE $K$ Real estate, renting and business activities, NACE L Public administration and defence, $N A C E M$ Education, $N A C E N$ Health and social work, NACE $O$ Other community, social and personal service activities. Sectors according to $N A C E B$, and $N A C E P$, and NACE $Q$ are excluded.

\begin{tabular}{|c|c|c|c|c|c|c|c|c|c|}
\hline \multicolumn{10}{|c|}{ Profession group (Occupation/Industry) } \\
\hline \multirow{2}{*}{\multicolumn{5}{|c|}{$\begin{array}{l}\text { 1: Management/Production, trade } \\
\text { 2: Management/Public, private }\end{array}$}} & \multicolumn{5}{|c|}{ 8: All occupations/Health, social work } \\
\hline & & & & & \multicolumn{5}{|c|}{ 9: Manual/Production, service } \\
\hline \multicolumn{5}{|c|}{ 3: Management/Public } & \multicolumn{5}{|c|}{ 10: Elementary/Public, private } \\
\hline \multicolumn{5}{|c|}{ 4: All occupations/Natural resources } & \multicolumn{5}{|c|}{ 11: Service work/Service } \\
\hline \multicolumn{5}{|c|}{ 5: All occupations/Energy, utilities } & \multicolumn{5}{|c|}{ 12: Service work/Production } \\
\hline \multicolumn{5}{|c|}{ 6: All occupations/Hotel,restaurants } & \multicolumn{5}{|c|}{ 13: All occupations/Agricultural } \\
\hline \multirow{2}{*}{\multicolumn{10}{|c|}{ 7: All occupations/Transport, communication 14: All o }} \\
\hline \multirow{2}{*}{\multicolumn{10}{|c|}{$\frac{\mathrm{ISCO}-88}{5}$}} \\
\hline & & & & & & & & & \\
\hline NACE A & 13 & 2 & 2 & 2 & 13 & 13 & 9 & 13 & 13 \\
\hline NACE C & 4 & 4 & 4 & 4 & 12 & - & 4 & 4 & 4 \\
\hline NACE D & 1 & 1 & 1 & 1 & 12 & 13 & 9 & 9 & 9 \\
\hline NACE E & 5 & 5 & 5 & 5 & 12 & - & 5 & 5 & 5 \\
\hline NACE F & 1 & 2 & 1 & 1 & 12 & 13 & 9 & 9 & 9 \\
\hline NACE G & 1 & 1 & 1 & 1 & 12 & 13 & 9 & 9 & 10 \\
\hline NACE H & 6 & 6 & 6 & 6 & 6 & 6 & 9 & 9 & 6 \\
\hline NACE I & 7 & 7 & 7 & 7 & 7 & 13 & 7 & 7 & 7 \\
\hline NACE J & 14 & 14 & 14 & 14 & 11 & 14 & 14 & 14 & 10 \\
\hline NACE K & 1 & 3 & 1 & 1 & 11 & 13 & 9 & 10 & 10 \\
\hline NACE L & 2 & 2 & 2 & 2 & 11 & 13 & 9 & 10 & 10 \\
\hline NACE M & 3 & 3 & 3 & 3 & 11 & 13 & 9 & 10 & 10 \\
\hline NACE N & 8 & 3 & 8 & 8 & 8 & 8 & 9 & 8 & 10 \\
\hline NACE O & 3 & 3 & 3 & 3 & 11 & 13 & 9 & 9 & 10 \\
\hline
\end{tabular}


Table 3: Lognormal regression of residence spells. Table reports ML estimates of lognormal regression of residence spells, see Eq. A2. Standard errors are robust towards serial correlation. LR-Statistic reports $\chi^{2}$-statistic for the null hypothesis that all coefficients in Eq. A2 are jointly zero. Wald-Statistic reports $\chi^{2}$-statistic for the null hypothesis that reported coefficients on profession dummies are jointly zero. ${ }^{* * *}$ significant at $1 \%$-level $* *$ significant at $5 \%$-level * significant at $10 \%$-level.

\begin{tabular}{lcc}
\hline \hline \multicolumn{2}{c}{ Dependent variable: Log residence duration } \\
\hline Employment income & $0.003^{* * *}$ & {$[0.001]$} \\
No assets & $-0.234^{* * *}$ & {$[0.043]$} \\
House price/Hh. income & $-0.003^{* *}$ & {$[0.001]$} \\
Age & $0.026^{* * *}$ & {$[0.002]$} \\
Education & $-0.019^{* * *}$ & {$[0.009]$} \\
Female & -0.032 & {$[0.038]$} \\
Household size & $0.138^{* * *}$ & {$[0.022]$} \\
Children & -0.096 & {$[0.059]$} \\
Married & $0.433^{* * *}$ & {$[0.044]$} \\
Foreigner & $-0.077^{*}$ & {$[0.043]$} \\
Unemployed & $-0.118^{*}$ & {$[0.071]$} \\
Profession1 & $0.295^{* * *}$ & {$[0.082]$} \\
Profession2 & $0.252^{* *}$ & {$[0.101]$} \\
Profession3 & $0.282^{* * *}$ & {$[0.094]$} \\
Profession4 & -0.099 & {$[0.201]$} \\
Profession5 & 0.072 & {$[0.152]$} \\
Profession7 & $0.299^{* * *}$ & {$[0.098]$} \\
Profession8 & $0.246^{* * *}$ & {$[0.091]$} \\
Profession9 & $0.277^{* * *}$ & {$[0.080]$} \\
Profession10 & $0.252^{* *}$ & {$[0.115]$} \\
Profession11 & $0.311^{* *}$ & {$[0.134]$} \\
Profession12 & $0.346^{* * *}$ & {$[0.114]$} \\
Profession13 & $0.441^{* * *}$ & {$[0.168]$} \\
Profession14 & $0.303^{* * *}$ & {$[0.104]$} \\
Region dummies & Yes & \\
Time dummies & Yes & \\
\hline$\widehat{\sigma}_{\varepsilon}$ & 1.007 & {$[0.012]$} \\
\hline LR-Statistics & $1076.43^{* * *}$ Obs. \\
Wald-Statistics & $23.49^{* *}$ Log Lik. & $-6,369$ \\
\hline \hline & & \\
\hline
\end{tabular}


Table 4: Summary statistics of income and rent. Variables are at the level of profession-region cells. Standard errors are in square brackets. Rent growth and income growth are measured with the constant-quality rent and income index series, respectively. Median monthly gross rent and income come from the 1995 GSOEP wave, converted into year 2000 Euros.

\begin{tabular}{lccc}
\hline \hline & Professions & \multicolumn{2}{c}{ Regions } \\
& $1985-2004$ & $1985-2004$ & 1995 \\
\hline Profession-specific real income growth & & & \\
Avg. real income growth & 0.012 & & \\
& {$[0.036]$} & & \\
S.d. of real income growth & 0.034 & & 2223.42 \\
& {$[0.013]$} & & {$[245.80]$} \\
Real median income & & & \\
Region-specific real rent growth & & 0.014 & \\
Avg. Real rent growth & & {$[0.041]$} & \\
S.d. of real rent growth & & 0.039 & \\
& & {$[0.017]$} & \\
Real median rent & & & {$[39.712]$} \\
& & & 30 \\
\hline Observations & 280 & 600 & 30 \\
\hline \hline
\end{tabular}


Table 5: Partial effects from bivariate probit model for recent movers. Table reports joint ML estimates of Eqs. 8 and 9. Partial effects (PE) are evaluated at sample averages of explanatory variables. Bootstrap standard errors are reported in parenthesis. Number of bootstrap replications is 200. LR-Statistic reports $\chi^{2}$-statistic for the null hypothesis that all coefficients in Eq. 8 are jointly zero. ${ }^{* * *}$ significant at $1 \%$-level ${ }^{* *}$ significant at $5 \%$-level $*$ significant at $10 \%$-level.

\begin{tabular}{|c|c|c|c|c|}
\hline \multirow[t]{2}{*}{ Specification } & \multicolumn{2}{|c|}{ 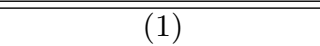 } & \multicolumn{2}{|c|}{$\overline{(2)}$} \\
\hline & $\begin{array}{l}\text { Mover } \\
\text { (Coef.) }\end{array}$ & $\begin{array}{c}\text { Renter } \\
(\mathrm{PE})\end{array}$ & $\begin{array}{l}\text { Mover } \\
\text { (Coef.) }\end{array}$ & $\begin{array}{c}\text { Renter } \\
(\mathrm{PE})\end{array}$ \\
\hline$m_{h, t}$ & & $\begin{array}{l}-0.015^{* * *} \\
{[0.005]}\end{array}$ & & $\begin{array}{c}-0.003 \\
{[0.002]}\end{array}$ \\
\hline$d_{h, t}$ & & $\begin{array}{c}-0.136 \\
{[0.095]}\end{array}$ & & $\begin{array}{r}0.012 \\
{[0.061]}\end{array}$ \\
\hline Employment income & $\begin{array}{c}-0.001 \\
{[0.001]}\end{array}$ & & $\begin{array}{c}-0.001 \\
{[0.001]}\end{array}$ & $\begin{array}{l}-0.001^{* *} \\
{[0.000]}\end{array}$ \\
\hline No assets & $\begin{array}{c}0.184^{* * *} \\
{[0.031]}\end{array}$ & & $\begin{array}{c}0.178^{* * *} \\
{[0.030]}\end{array}$ & $\begin{array}{c}0.057^{\text {*** }} \\
{[0.020]}\end{array}$ \\
\hline House price/Hh. income & $\begin{array}{l}-0.002^{*} \\
{[0.001]}\end{array}$ & & $\begin{array}{l}-0.003^{* *} \\
{[0.001]}\end{array}$ & $\begin{array}{l}0.007^{* * *} \\
{[0.002]}\end{array}$ \\
\hline Age & $\begin{array}{l}-0.027^{* * *} \\
{[0.001]}\end{array}$ & & $\begin{array}{l}-0.027^{* * *} \\
{[0.001]}\end{array}$ & $\begin{array}{l}-0.002 \\
{[0.001]}\end{array}$ \\
\hline Education & $\begin{array}{r}0.007 \\
{[0.005]}\end{array}$ & & $\begin{array}{c}0.009^{* *} \\
{[0.005]}\end{array}$ & $\begin{array}{l}-0.004^{* *} \\
{[0.002]}\end{array}$ \\
\hline Female & $\begin{array}{c}-0.004 \\
{[0.024]}\end{array}$ & & $\begin{array}{r}0.001 \\
{[0.005]}\end{array}$ & $\begin{array}{r}0.000 \\
{[0.010]}\end{array}$ \\
\hline Household size & $\begin{array}{l}-0.047^{* * *} \\
{[0.011]}\end{array}$ & & $\begin{array}{l}-0.050^{* * *} \\
{[0.011]}\end{array}$ & $\begin{array}{l}-0.017^{* *} \\
{[0.008]}\end{array}$ \\
\hline Children & $\begin{array}{c}-0.032 \\
{[0.035]}\end{array}$ & & $\begin{array}{r}-0.023 \\
{[0.034]}\end{array}$ & $\begin{array}{r}-0.010 \\
{[0.015]}\end{array}$ \\
\hline Married & $\begin{array}{l}-0.219^{* * *} \\
{[0.027]}\end{array}$ & & $\begin{array}{l}-0.206^{* * *} \\
{[0.025]}\end{array}$ & $\begin{array}{l}-0.077^{* * *} \\
{[0.024]}\end{array}$ \\
\hline Foreigner & $\begin{array}{l}0.130^{* * *} \\
{[0.026]}\end{array}$ & & $\begin{array}{l}0.110^{* * *} \\
{[0.025]}\end{array}$ & $\begin{array}{l}0.083^{* * *} \\
{[0.024]}\end{array}$ \\
\hline Increase in Hh. size & $\begin{array}{l}0.643^{* * *} \\
{[0.033]}\end{array}$ & & $\begin{array}{l}0.639^{* * *} \\
{[0.032]}\end{array}$ & \\
\hline Decrease in Hh. size & $\begin{array}{l}0.338^{* * *} \\
{[0.040]}\end{array}$ & & $\begin{array}{l}0.331^{* * *} \\
{[0.039]}\end{array}$ & \\
\hline Increase in children & $\begin{array}{l}-0.196^{* * *} \\
{[0.062]}\end{array}$ & & $\begin{array}{l}-0.197^{* * *} \\
{[0.062]}\end{array}$ & \\
\hline Decrease in children & $\begin{array}{r}0.046 \\
{[0.062]}\end{array}$ & & $\begin{array}{r}0.040 \\
{[0.061]}\end{array}$ & \\
\hline Become married & $\begin{array}{c}0.436^{* * *} \\
{[0.050]}\end{array}$ & & $\begin{array}{l}0.440^{* * *} \\
{[0.045]}\end{array}$ & \\
\hline Become divorced & $\begin{array}{r}0.080 \\
{[0.076]}\end{array}$ & & $\begin{array}{r}0.087 \\
{[0.077]}\end{array}$ & \\
\hline Become employed & $\begin{array}{l}0.246^{* * *} \\
{[0.040]}\end{array}$ & & $\begin{array}{c}0.249^{* * *} \\
{[0040 .]}\end{array}$ & \\
\hline Become unemployed & $\begin{array}{l}0.152^{* * *} \\
{[0.059]}\end{array}$ & & $\begin{array}{l}0.156^{* * *} \\
{[0.037]}\end{array}$ & \\
\hline Time dummies & Yes & Yes & Yes & Yes \\
\hline Region dummies & Yes & Yes & Yes & Yes \\
\hline Profession dummies & Yes & No & Yes & No \\
\hline$\rho$ & & $-0.302^{* * *}$ & & $-0.457^{* * *}$ \\
\hline LR-Statistic & & $198.74^{* * *}$ & & $776.43^{* * *}$ \\
\hline Log Likelihood & & $-15,318$ & & $-15,029$ \\
\hline Observations & 52,413 & 4,254 & 52,413 & 4,254 \\
\hline
\end{tabular}


Table 6: Partial effects and average partial effects from dynamic panel probit regressions. Table reports partial effects from pooled probit regressions, using Eq. 10 and assuming independent $c_{h}$, and average partial effects from correlated random effects regressions, Eqs. 12 and 13. Partial effects are calculated at sample averages of explanatory variables. Effects for $y_{h, 0}$ is not reported. Bootstrap standard errors are reported in parenthesis. Number of bootstrap replications is 200. $\bar{\chi}^{2}$-Statistic is for likelihood ratio test of the null hypothesis that $\theta=\sigma_{a}^{2} /\left(\sigma_{a}^{2}+1\right)$ is zero. LR-Statistic reports $\chi^{2}$-statistic for the null hypothesis that all coefficients in Eqs. 10 and 12 are jointly zero. ${ }^{* * *}$ significant at $1 \%$-level ** significant at $5 \%$-level $*$ significant at $10 \%$-level.

\begin{tabular}{|c|c|c|c|c|}
\hline \multicolumn{5}{|c|}{ Binary dependent variable: Household is renter } \\
\hline \multirow[b]{2}{*}{ Specification } & \multicolumn{2}{|c|}{ Pooled probit } & \multicolumn{2}{|c|}{ Correlated RE } \\
\hline & (1) & $(2)$ & (3) & (4) \\
\hline \multirow{2}{*}{$y_{h, t-1}$} & $0.946^{* * *}$ & $0.943^{* * *}$ & $0.504^{* * *}$ & $0.576^{* * *}$ \\
\hline & {$[0.003]$} & {$[0.003]$} & {$[0.040]$} & {$[0.037]$} \\
\hline \multirow{2}{*}{$m_{h, t}$} & $-0.013^{* * *}$ & $-0.017^{* * *}$ & $-0.013^{* * *}$ & $-0.011^{* *}$ \\
\hline & {$[0.001]$} & {$[0.004]$} & {$[0.002]$} & {$[0.004]$} \\
\hline \multirow[t]{2}{*}{$d_{h, t}$} & -0.138 & -0.008 & 0.031 & 0.043 \\
\hline & {$[0.100]$} & {$[0.100]$} & {$[0.125]$} & {$[0.137]$} \\
\hline \multirow[t]{2}{*}{ Employment income } & & 0.000 & & 0.000 \\
\hline & & {$[0.000]$} & & {$[0.000]$} \\
\hline \multirow[t]{2}{*}{ No assets } & & $0.064^{* *}$ & & 0.003 \\
\hline & & {$[0.027]$} & & {$[0.023]$} \\
\hline \multirow[t]{2}{*}{ House price/Hh. income } & & $0.006^{* * *}$ & & $0.003^{* *}$ \\
\hline & & {$[0.001]$} & & {$[0.001]$} \\
\hline \multirow[t]{2}{*}{ Age } & & $0.006^{* * *}$ & & 0.001 \\
\hline & & {$[0.001]$} & & {$[0.002]$} \\
\hline \multirow[t]{2}{*}{ Education } & & $-0.015^{* * *}$ & & -0.010 \\
\hline & & {$[0.003]$} & & {$[0.007]$} \\
\hline \multirow[t]{2}{*}{ Female } & & -0.028 & & -0.029 \\
\hline & & {$[0.020]$} & & {$[0.022]$} \\
\hline \multirow[t]{2}{*}{ Household size } & & 0.015 & & -0.016 \\
\hline & & {$[0.010]$} & & {$[0.011]$} \\
\hline \multirow[t]{2}{*}{ Children } & & $-0.037 *$ & & 0.005 \\
\hline & & {$[0.020]$} & & {$[0.022]$} \\
\hline \multirow[t]{2}{*}{ Married } & & $-0.076^{* * *}$ & & $-0.061^{* *}$ \\
\hline & & [0.024] & & {$[0.029]$} \\
\hline \multirow[t]{2}{*}{ Foreigner } & & $0.180^{* * *}$ & & $0.170^{* * *}$ \\
\hline & & {$[0.017]$} & & {$[0.020]$} \\
\hline Time dummies & Yes & Yes & Yes & Yes \\
\hline Region dummies & Yes & Yes & Yes & Yes \\
\hline Missing dummies & No & No & Yes & Yes \\
\hline & & & 1.216 & 0.987 \\
\hline $\bar{\chi}^{2}$-Statistic & & & $220.190^{* * *}$ & $161.24^{* * *}$ \\
\hline LR-Statistic & $42,300^{* * *}$ & $9,458^{* * *}$ & $42,685^{* * *}$ & $9,807^{* * *}$ \\
\hline Log Likelihood & $-4,165$ & $-3,908$ & $-3,973$ & $-3,733$ \\
\hline Observations & 36,625 & 36,625 & 36,625 & 36,625 \\
\hline
\end{tabular}




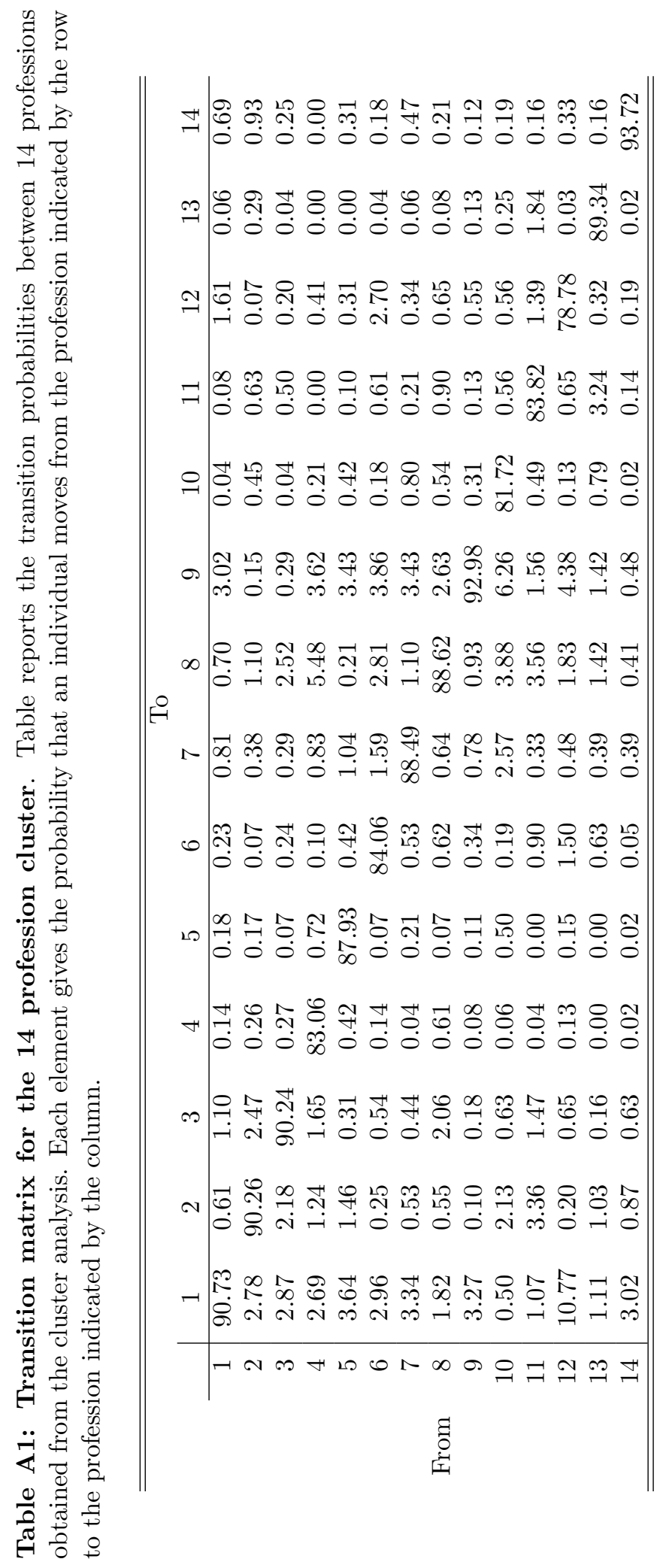


Table A2: Summary statistics for residence spells, 1985-2004. Number of observations is 29,369 which comprise 6,842 spells. Maximal length of spell covers censored and uncensored spells. Age is age of household head at the beginning of the spell. Employment income is yearly income from employment of household head in real (year 2000) Euros. Price-income ratio is the ratio of the average price of a single-family dwelling of average quality with yearly household income. Data for regional house prices are provided by the RDM.

\begin{tabular}{lrrr}
\hline \hline & Mean & Median & Std. Dev. \\
\hline Dependent variable & & & \\
Maximal length of spell & 4.856 & 3.000 & 4.070 \\
Continuous characteristics & & & \\
Age & 34.078 & 32.000 & 9.208 \\
Education & 11.723 & 11.000 & 2.788 \\
Household Size & 2.737 & 3.000 & 1.386 \\
Employment income (000) & 27.456 & 25.478 & 17.823 \\
House price/Hh. income & 12.402 & 10.221 & 9.875 \\
Discrete characteristics & & & \\
Female & 0.305 & & \\
Children & 0.467 & & \\
Married & 0.598 & & \\
No assets & 0.109 & & \\
Unemployed & 0.050 & & \\
Foreigner & 0.239 & & \\
\hline \hline
\end{tabular}

Table A3: Hedonic repeat-measures income regression. Table reports fixed effects estimates of Eq. A3. Time dummies, and region dummies are not reported. $T(\cdot)$ is the Box-Cox type transformation function suggested by Bunke et al (1999). Standard errors are calculated with the robust covariance estimator suggested by Arellano (1987). *** significant at $1 \%$-level $* *$ significant at $5 \%$-level $*$ significant at $10 \%$-level.

\begin{tabular}{|c|c|c|}
\hline \multicolumn{3}{|c|}{ Dependent variable: Log employment income } \\
\hline$T$ (Age) & $16.699^{* * *}$ & {$[0.384]$} \\
\hline$T(\text { Age })^{2}$ & $-22.381^{* * *}$ & {$[0.690]$} \\
\hline Education & $0.060^{* * *}$ & {$[0.002]$} \\
\hline Experience & $0.048^{* * *}$ & {$[0.002]$} \\
\hline Experience $^{2}$ & $-0.001^{* * *}$ & {$[0.000]$} \\
\hline$T$ (Workhours) & $-114.697^{* * *}$ & {$[7.866]$} \\
\hline$T{\text { (Workhours })^{2}}^{2}$ & $142.569^{* * *}$ & [8.597] \\
\hline Duration of employment & $0.003^{* * *}$ & {$[0.000]$} \\
\hline Observations & $107,073 \quad R^{2}$ & 0.614 \\
\hline Workers & $15,701 \quad \widehat{\sigma}_{c}$ & 0.429 \\
\hline
\end{tabular}


Table A4: Hedonic repeat-measures rent regression. Table reports fixed effects estimates of Eq. A5. Time dummies are not reported. Standard errors are calculated with the robust covariance estimator suggested by Arellano (1987). *** significant at $1 \%$-level ** significant at $5 \%$-level * significant at $10 \%$-level.

\begin{tabular}{|c|c|c|}
\hline \multicolumn{3}{|c|}{ Dependent variable: Log rent } \\
\hline No bathroom & $-0.093^{* * *}$ & {$[0.012]$} \\
\hline No central heating & $-0.059^{* * *}$ & {$[0.007]$} \\
\hline Subsidized housing & $-0.023^{* * *}$ & {$[0.004]$} \\
\hline 1-5 yrs. of occup. & $-0.015^{* * *}$ & {$[0.005]$} \\
\hline 6-10 yrs. of occup. & $-0.018^{* * *}$ & {$[0.006]$} \\
\hline 11-15 yrs. of occup. & $-0.016^{* *}$ & {$[0.007]$} \\
\hline 16-20 yrs. of occup. & -0.014 & {$[0.010]$} \\
\hline $21>$ yrs. of occup. & -0.006 & {$[0.012]$} \\
\hline Observations & 53,544 & 0.320 \\
\hline Dwellings & 9,852 & 0.423 \\
\hline
\end{tabular}

